\title{
Avaliação das melhorias obtidas por meio da implantação do projeto de alvenaria de vedação
}

\author{
Assessment of improvements through by the \\ implementation of masonry partition design
}

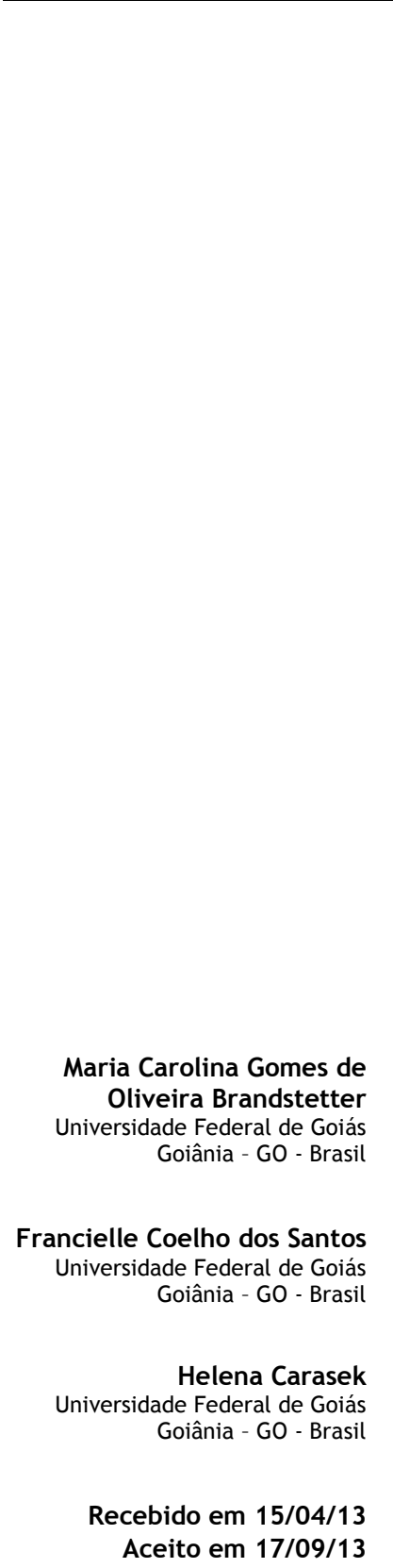

\section{Maria Carolina Gomes de Oliveira Brandstetter Francielle Coelho dos Santos Helena Carasek}

\section{Resumo}

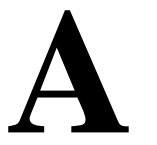

implantação do projeto de alvenaria propicia um instrumento de racionalização visando melhorias no processo de produção em canteiros de obras. O presente trabalho teve como objetivo avaliar e quantificar as melhorias obtidas no processo de execução de alvenaria de vedação por meio da implantação do projeto para a produção, em um empreendimento da região metropolitana de Goiânia. O estudo do processo de execução de alvenaria foi dividido em dois momentos distintos: antes e após a implantação do projeto, nos quais foram avaliados a produtividade e o consumo de blocos cerâmicos do serviço executado. Para a avaliação das melhorias, os dados foram tratados por meio de análises estatísticas. Como principais resultados, observou-se o aumento da produtividade potencial da equipe na ordem de $15 \%$ e as análises de regressões lineares confirmaram a tendência do efeito aprendizado após a implantação do projeto para produção. O percentual de elevações que tiveram um consumo real menor ou igual ao consumo de referência obtido em projeto passou de $38 \%$ para $80 \%$ após a implantação do projeto. A principal contribuição deste trabalho está relacionada ao método de avaliação do impacto causado pela implantação do projeto para a produção da alvenaria na produtividade e nas perdas de materiais.

Palavras-chave: Projeto. Produtividade. Perda. Alvenaria. Vedação.
Abstract
The implementation of masonry design provides a rationalizing tool for improving the production process in construction sites. The aim of this research work is to assess and quantify the improvements obtained in the non-structural masonry execution process by the implementation of process design, in a project located in Goiania Metropolitan Area. This study was divided in two different moments: before and after the implementation of the process design, in which the productivity and the consumption of ceramic blocks were monitored. For the assessment of the improvements achieved, data were treated by statistical analysis. As main results, there was a $15 \%$ increase in the potential productivity, and the linear regression analysis confirmed the trend of a learning effect after the implementation of the process design. The percentage of walls that had an actual consumption less than or equal to the expected one has changed from $38 \%$ to $80 \%$ after the implementation of the process design. The main contribution of this paper is related to the method for assessing the impact of the implementation of the masonry process design implementation in productivity and material waste. Keywords: Project. Productivity. Waste. Masonry. Partition. 


\section{Introdução}

Diante de um mercado consumidor cada vez mais exigente quanto à qualidade dos produtos $\mathrm{e}$ serviços oferecidos pela indústria, o setor da construção civil procura, cada vez mais, se adequar no que diz respeito às necessidades de seus clientes, ao desenvolvimento e implantação de novas tecnologias, à capacitação de novos profissionais e à busca de maior eficiência. Para tanto, as novas relações econômicas estabelecem maior competitividade entre as empresas, fazendo que cresçam as atenções com a melhoria do desempenho.

Entre as diversas novas formas de produção, passíveis de ser empregadas, muitas empresas começaram a investir no incremento de seus atuais processos produtivos por meio da racionalização construtiva ou da implantação de novas tecnologias. Essas novas ações de gestão por uma maior eficiência nos processos de produção podem sofrer alterações em todas as fases e departamentos (planejamento, projeto, execução, controle, suprimentos, mercado, recursos humanos e assistência técnica), implicando a realização de inúmeras atividades técnicas, administrativas e financeiras, as quais precisam de uma efetiva coordenação para cada fase entre elas, de modo a propiciar o resultado esperado em termos de prazo, qualidade e custos (HOLANDA, 2003; PEÑA, 2003; HWANG; YEO, 2011).

Entretanto, a obtenção de maior eficiência por parte da empresa, refletida na melhoria de sua produtividade, demanda uma etapa anterior ao conhecimento do desempenho vigente, bem como dos fatores atuantes sobre o processo, que possam induzir sobre as causas das falhas no mesmo. Para que se tenha uma gestão eficiente é necessário que se conheçam, a priori, os níveis de desempenho possíveis de ser alcançados na utilização dos recursos físicos no canteiro de obras. Com o conhecimento desses níveis, os gerentes de obra têm noção de eventuais problemas, para tomar as medidas corretivas necessárias, podendo justificar e viabilizar a adoção de novas posturas (ANDRADE; SOUZA, 2000; ARAÚJO, 2000).

Em função das interfaces com os demais subsistemas do edifício, a vedação vertical é de grande importância na racionalização da obra como um todo. O projeto de vedação deve ser elaborado de forma sistêmica, simultaneamente aos demais projetos, permitindo, assim, uma coordenação das informações e das soluções técnicas a serem adotadas. A qualidade do projeto e do empreendimento envolve não apenas a gestão dos processos em cada empresa, mas também a articulação entre os processos dessas empresas (PEÑA, 2003).

Nesse sentido, a antiga alvenaria, caracterizada pela baixa produtividade e regularidade geométrica insatisfatória, vem dando lugar a novas tecnologias de produção de vedações verticais, que buscam a interação com todos os subsistemas que a cercam, principalmente estrutura, sistemas prediais hidráulicos, sanitários e elétricos, impermeabilizações e revestimentos.

É esse contexto que se justifica a relevância do tema desta pesquisa. O processo de projeto de alvenaria de vedação para construção de edifícios é analisado sob uma perspectiva sistêmica, em que se observam as questões da qualidade e eficiência, especialmente os mecanismos de avaliação e retroalimentação, como subsídio para melhoria contínua dos processos e produtos, capazes de diminuir as incertezas e aumentar a eficiência da execução do serviço.

Partindo-se do princípio de que a implantação do projeto para a produção das alvenarias de vedação é um instrumento de racionalização que pode gerar melhorias no processo executivo no canteiro de obras, o presente trabalho teve como objetivo quantificar, por tratamentos estatísticos, as melhorias relacionadas à produtividade e ao consumo de materiais obtidas no processo de produção de alvenaria de vedação por meio da implantação do projeto para a produção.

Cabe ressaltar a originalidade da pesquisa quanto ao objetivo proposto, dada a escassez de trabalhos nos âmbitos nacional e internacional que trataram da avaliação de forma quantitativa das melhorias obtidas a partir da implantação do projeto de alvenaria. Assim, a pesquisa apresentada também contribui de forma inédita com a abordagem da quantificação dos benefícios advindos da realização de uma intervenção em obra, a implantação do projeto para a produção da alvenaria de vedação. Ademais, busca-se contribuir com o método proposto para a avaliação do impacto causado pela implantação do projeto para a produção de alvenaria na produtividade e nas perdas de materiais.

\section{Projeto para produção de alvenaria de vedação}

O projeto de vedação vertical é item fundamental para a implantação das tecnologias construtivas racionalizadas, isto é, interfere na racionalização do edifício como um todo. Para a produção dessa etapa dos serviços, preferencialmente deve ser 
desenvolvida de forma simultânea ao detalhamento do projeto executivo, permitindo, assim, uma coordenação das informações e das soluções técnicas a serem adotadas (LORDSLEEM JUNIOR, 2000; FRANCO, 1998; PEÑA, 2003). A racionalização da produção vertical, por sua vez, é fundamental para a racionalização de todos os demais subsistemas que compõem o edifício e, consequentemente, propicia diminuição de desperdícios e economia de materiais e mão de obra, proporcionando o aumento da produtividade das atividades.

A adoção de projeto para produção de alvenaria funciona, portanto, no primeiro momento, como instrumento de compatibilização e de coordenação não só entre projetos arquitetônico e complementares e demais documentos de obra, mas também como elemento de integração entre a fase de concepção e a de produção, ao buscar incorporar soluções construtivas consoantes com a realidade dos canteiros (SILVA, 2003).

De acordo com Aquino e Melhado (2005), o desenvolvimento do projeto para produção de vedações verticais requer um esforço consciente dos diversos agentes do processo de produção, que resulte em ações integradas na busca do conhecimento da tecnologia construtiva empregada pelas empresas construtoras e suas interferências no canteiro de obras, dos materiais e equipamentos empregados, da análise do custo/benefício das propostas de projeto, desempenho do subsistema, logística do canteiro e controle do processo de produção, que, somadas a uma retroalimentação eficiente, geram ações de melhoria para futuros projetos e para todo o processo de produção.

Para iniciar-se o estudo do projeto de alvenaria de vedação são analisados e compatibilizados os projetos arquitetura, estrutura e instalações, pois, segundo Silva (2003), são nas interfaces com os outros subsistemas que se revelam mais plenamente os efeitos das movimentações diferenciadas entre materiais distintos, devido aos diferentes coeficientes de dilatação térmica, de variações volumétricas sob a ação da umidade ou de composição química que os caracterizam; essas interfaces deverão ser objeto do detalhamento construtivo visando a tensões que tendam a se dissipar nas regiões onde ocorrem descontinuidades.

Quanto a seu conteúdo, o projeto deve apresentar a especificação de todos os materiais de construção necessários (incluindo traços indicativos das argamassas de assentamento e fixação), memorial descritivo da construção (forma de locação das paredes, execução dos cantos, escoramentos provisórios diante da ação do vento, prazos entre execução da estrutura, elevação das paredes, interface alvenaria/estrutura, forma de fixação de marcos e contramarcos) e todos os elementos gráficos necessários (THOMAZ; HELENE, 2000). Núcleo de Tecnologia das Argamassas e Revestimentos (2010), Peña (2003), Silva (2003), Lordsleem Jr. (2000) e Barros (1998) destacam que a maioria dos projetos elaborados apresenta como escopo básico:

(a) especificação dos componentes de alvenaria: tipo de bloco, composição e dosagem da argamassa de assentamento;

(b) plantas de marcação de primeira fiada, que traz incorporada a compatibilização dos projetos de arquitetura, estrutura, instalações, impermeabilização, esquadrias, já associadas a uma distribuição horizontal dos blocos (Figura 1);

(c) caderno de elevações, onde são apresentadas elevações de todas as paredes, contendo as interferências com componentes do subsistema de instalações prediais de qualquer natureza, aberturas das esquadrias ou quadros de distribuição ou outros elementos (Figura 2); e

(d) especificações técnicas complementares dos materiais e componentes indicados, forma de produção e aplicação, preparação da estrutura, fixações, componentes de amarração, prémoldados, definição da sequência de execução das alvenarias de vedação e de sua fixação à estrutura.

\section{Indicadores de desempenho relacionados à execução da alvenaria de vedação}

Entende-se por indicadores como a representação das informações quantitativas ou qualitativas que medem e avaliam o comportamento de diferentes aspectos do objeto de estudo (SOUZA, 2005).

\section{Produtividade da mão de obra: enfoque no processo de alvenaria}

A produtividade da mão de obra no ambiente nacional da construção passou a ser objeto de pesquisa, com destaque a partir da década de 90 , com publicações de Heineck (1991) sobre o efeito aprendizagem no processo de alvenaria de vedação, provando que a continuidade do trabalho pode gerar um potencial aumento de produtividade da ordem de $50 \%$, bem como a publicação de Scardoelli, Bicca e Formoso (1994), que estudam os tempos produtivos, auxiliares e improdutivos e os relacionam com problemas gerenciais. 
Figura 1 - Exemplo genérico - planta de marcação de primeira fiada

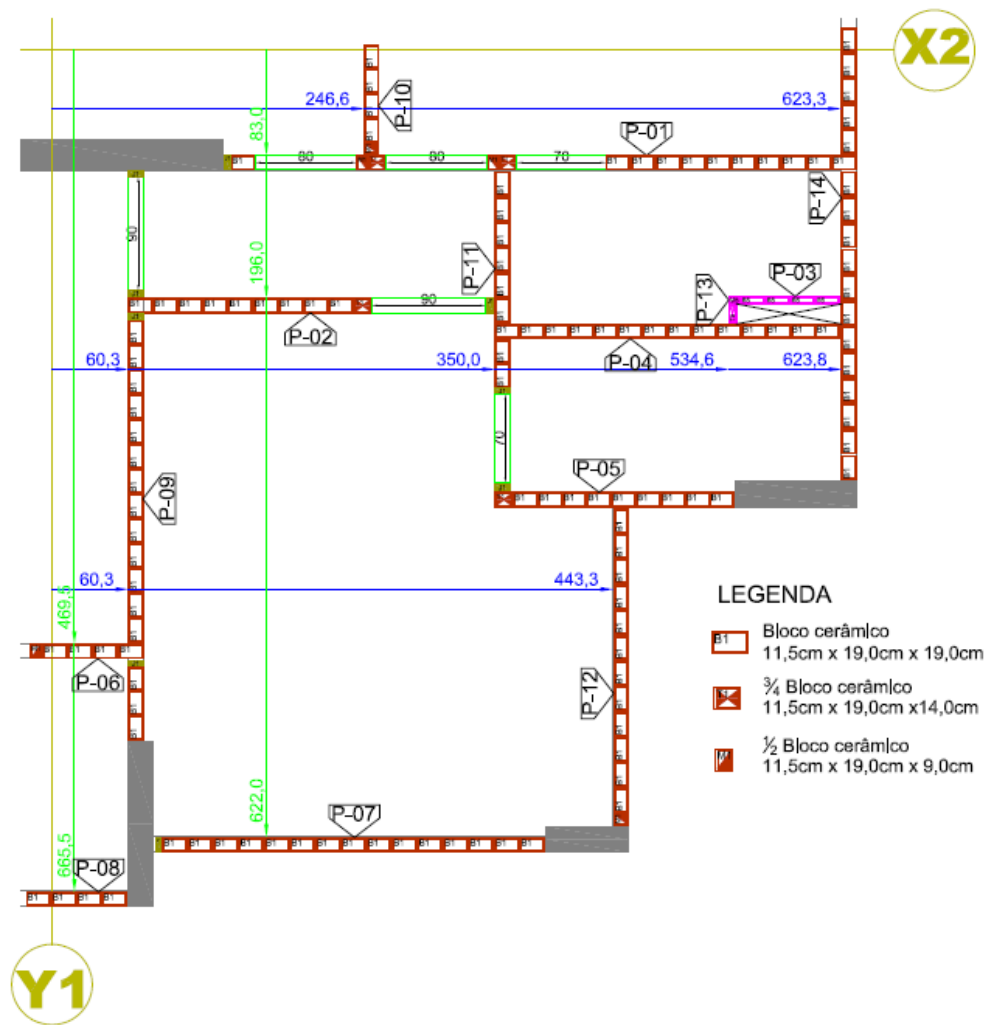

Fonte: Núcleo de Tecnologia das Argamassas e Revestimentos (2010).

Figura 2 - Exemplo genérico - Elevação de alvenaria

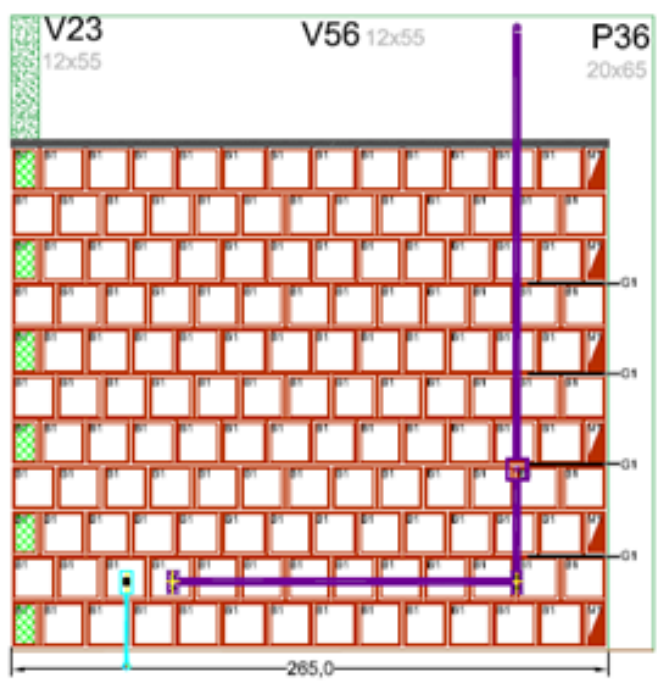

\section{Elevaçăo P-12}

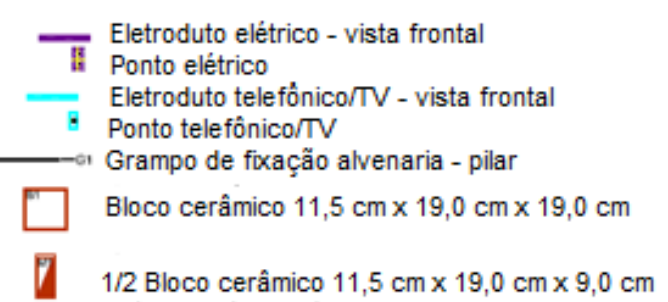

Fonte: Núcleo de Tecnologia das Argamassas e Revestimentos (2010).

Em 1996, Souza fundamenta sua tese em uma metodologia padronizada de medição da produtividade da mão de obra, por meio do Modelo dos Fatores, proposto por Thomas e Yiakoumis (1987), que permite detectar quais fatores influenciam a produtividade e como quantificar tal influência, estabelecendo o indicador Razão Unitária de Produção. Especificamente para a alvenaria de vedação, este método foi aplicado no trabalho de Carraro (1998), destacando-se os aspectos de simplicidade de coleta, baixo custo de aplicação e agilidade nas respostas.

82 Brandstetter, M. C. G. de O.; Santos, F. C. dos; Carasek, H. 
Em 2000, Araújo também aplicou em canteiros de obras de São Paulo o Modelo dos Fatores para processos da construção, entre os quais a alvenaria de vedação, sugerindo uma lista de fatores potenciais influenciadores da produtividade da mão de obra.

Outros trabalhos buscaram facilitar decisões de gestão com base nos indicadores de produtividade, como o de Fachini (2005), que sugere como diretriz a decomposição do serviço em partes como subtarefas, e Marchiori (2009), que destaca a importância da influência do indicador de produtividade na adequação do orçamento como instrumento para a melhoria da gestão.

Assim como no cenário nacional, no âmbito internacional os estudos que trataram da produtividade da mão de obra da alvenaria não tiveram por objetivo a análise do impacto do projeto de produção, tendo, portanto, outros objetivos de investigação, cabendo destacar:

(a) Mortlock e Whitehead (1970) buscaram relacionar a produtividade a fatores tais como o tipo de bloco, o tamanho dos vãos, o uso de coordenação modular, proteção contra intempéries, uso de andaimes ajustáveis, utilização de auxílios mecânicos, programas de treinamento e melhoria da organização do trabalho;

(b) Sanders e Thomas (1993) propõem um modelo estatístico para previsão da produtividade da alvenaria considerando os efeitos diários de fatores ambientais e requisitos de projeto;

(c) Anand e Ramamurthy (2003) compararam tempos produtivos entre o processo convencional e a alvenaria de blocos intertravados, concluindo pela menor produtividade do método tradicional;

(d) Enshassi et al. (2007) estudaram nove projetos distintos na Palestina para estabelecimento de um benchmarking para o processo de alvenaria; e

(e) Hammad et al. (2008) compararam diferentes técnicas para a execução da alvenaria nos Estados Unidos, Reino Unido e Jordânia, concluindo que o método de trabalho e as habilidades dos operários têm influência maior na produtividade.

\section{Indicador de produtividade da mão de obra}

Considerando que um processo envolve a transformação de entradas (materiais, mão de obra, energia) em saídas (custo total, metro quadrado de alvenaria, unidade habitacional), a produtividade pode ser vista como a eficiência na transformação de tais entradas em saídas que cumpram com os objetivos previstos para tal processo (THOMAS; YIAKOUMIS, 1987; SOUZA, 2006).
Para o caso do subsistema de alvenaria de vedação, a quantidade de serviço é medida em área, e considera-se o tempo em que os operários estiveram disponíveis para o trabalho. Paliari (2008) recomenda que precisam ser considerados tanto os tempos produtivos quanto os improdutivos.

O indicador denominado Razão Unitária de Produção (RUP) é adotado como mensurador da produtividade da mão de obra, o qual relaciona a quantidade total de horas trabalhadas $\mathrm{e} a$ quantidade de serviço realizado pelas equipes em um mesmo período, estabelecido em $\mathrm{Hh} / \mathrm{m}^{2}$. O indicador cumulativo ( $\mathrm{RUP}_{\text {cumulativa }}$ ) relaciona a quantidade acumulada de homens-hora gastos desde o início da coleta com a quantidade produzida no mesmo período. $\mathrm{O}$ indicador potencial $\left(\right.$ RUP $\left._{\text {potencial }}\right)$ é calculado pela mediana das RUPs diárias que apresentam valores menores que o valor da RUP cumulativa no final do período estudado (SOUZA, 2005).

\section{Contexto das perdas de materiais na construção civil}

Perda de materiais pode ser definida como sendo toda a quantidade de material consumida além da quantidade teoricamente necessária, que é aquela indicada no projeto e seus memoriais, ou demais prescrições do executor para o produto sendo executado. Segundo o autor, essa definição delimita a discussão das perdas ao âmbito da produção, isto é, uma vez definido o projeto, este seria a referência a ser buscada no processo de produção e, portanto, haveria perda caso as atividades de produção levassem a uma necessidade de materiais superior àquela calculada com base nas prescrições do projeto (SKOYLES; SKOYLES, 1987; SOUZA, 2005).

A eliminação ou redução dos custos advindos do consumo de mão de obra, materiais e equipamentos, sem perda de qualidade do produto oferecido ou do serviço prestado, torna-se necessária e, para isso, há de se identificarem os pontos falhos dos processos envolvidos (HWANG; YEO, 2011).

Para Souza (2005), as perdas acontecem toda a vez que se estabelece um consumo de materiais superior ao teoricamente necessário, podendo ocorrer em diferentes momentos do empreendimento: concepção, produção da obra e utilização. $\mathrm{Na}$ fase de execução são várias as fontes de perdas possíveis: no recebimento e estocagem dos materiais e componentes, processamento intermediário, processamento final e movimentações entre as etapas do processo. 
As perdas medidas relacionadas às alvenarias de vedação são muito elevadas e, por essa razão, justificam os estudos na área. Um resumo dos resultados obtidos em estudos sobre perdas de componentes de alvenaria que se destacaram no cenário nacional é apresentado na Tabela 1.

\section{Indicadores de perda e consumo de materiais}

O conceito relativo de consumo de materiais deriva da definição de produtividade no uso de recursos físicos num processo produtivo (PALIARI, 2008). O consumo é a quantidade de materiais necessária para se produzir uma unidade de produto resultante do serviço em que esse material está sendo utilizado (SOUZA, 2005).

$\mathrm{O}$ indicador do consumo unitário de materiais (IC) indica a quantidade real de materiais $\left(\mathrm{C}_{\mathrm{REAL}}\right) \mathrm{em}$ que eles, sejam básicos, simples ou compostos, são utilizados para a realização de uma unidade de certo serviço (QS). Essa relação é expressa pela Equação 1.

$\mathrm{IC}=\frac{\text { Creal } *}{\mathrm{QS}}$

Eq. 1

Nesse sentido, Souza (2005) estabelece a diferença entre os indicadores de perda e de consumo. Enquanto o consumo unitário mede o desempenho ocorrido quanto ao consumo de materiais, o indicador de perdas avalia a discrepância do desempenho real com relação a um desempenho considerado de perda nula.

O conceito de perda consiste na diferença percentual entre quantidade real de material utilizada $\left(\mathrm{C}_{\mathrm{REAL}}\right)$ em um ou em diversos serviços (consumo real de material) e a quantidade teoricamente necessária $\left(\mathrm{C}_{\mathrm{REF}}\right)$ para a execução do serviço (consumo de referência) durante um período (PALIARI, 2008). O indicador de perdas, em termos percentuais, pode ser calculado pela Equação 2:
$I P(\%)=\left(\frac{C R E A L-C R E F}{C R E F}\right) \times 100$

Eq. 2

Nesse sentido, o percentual de perdas está determinado em relação à quantidade de material teoricamente necessária, com a intenção de expressar o distanciamento com relação ao que foi prescrito. A abordagem por perdas, ao fixar uma referência de perda nula, determina uma meta (SOUZA, 2005).

\section{Método de pesquisa}

O presente trabalho visou à investigação de um caso específico, delimitado e contextualizado em tempo e lugar, para que se pudesse realizar uma busca circunstanciada de informações. Teve por base uma investigação no processo de transformação no empreendimento estudado, que adotou em sua rotina processual o projeto de alvenaria de vedação. Isso foi realizado por meio do levantamento de dados para caracterização da empresa, incluindo a investigação dos procedimentos adotados pertinentes a seu sistema de gestão da qualidade. Esse levantamento visou à avaliação dos impactos da implantação desse novo processo no canteiro de obra, das dificuldades encontradas em seu desenvolvimento, no consumo de materiais e em sua utilização ao que ainda pode ser desenvolvido e melhorado.

Toda a pesquisa foi realizada em um período de dois anos e segue a estrutura cronológica apresentada na Figura 3.

Após a revisão bibliográfica, a primeira etapa consistiu na escolha do estudo de caso. A empresa selecionada tinha o projeto de alvenaria de vedação, porém não o utilizava na íntegra. Dessa forma, a empresa já possuía a conscientização para a melhoria do processo e implantação das soluções de modulação dos blocos cerâmicos.

Tabela 1 - Perdas de componentes de vedação segundo diversos autores e tipo de componentes

\begin{tabular}{l|c|c}
\hline Materiais relacionados à vedação & Perda & Autores \\
\hline COMPONENTES DE VEDAÇÃO & $13 \%$ & PINTO (1989) \\
\hline TIJOLO FURADO & $50 \%$ & SOIBELMAN (1993) \\
\hline TIJOLO MACIÇO & $54 \%$ & SOIBELMAN (1993) \\
\hline BLOCOS E TIJOLOS & $17 \%$ & AGOPYAN et al. (1998) \\
\hline BLOCOS E TIJOLOS & $17 \%$ & SOUZA et al. (1998) \\
\hline
\end{tabular}

84 Brandstetter, M. C. G. de O.; Santos, F. C. dos; Carasek, H. 
Figura 3 - Etapas cronológicas de realização da pesquisa

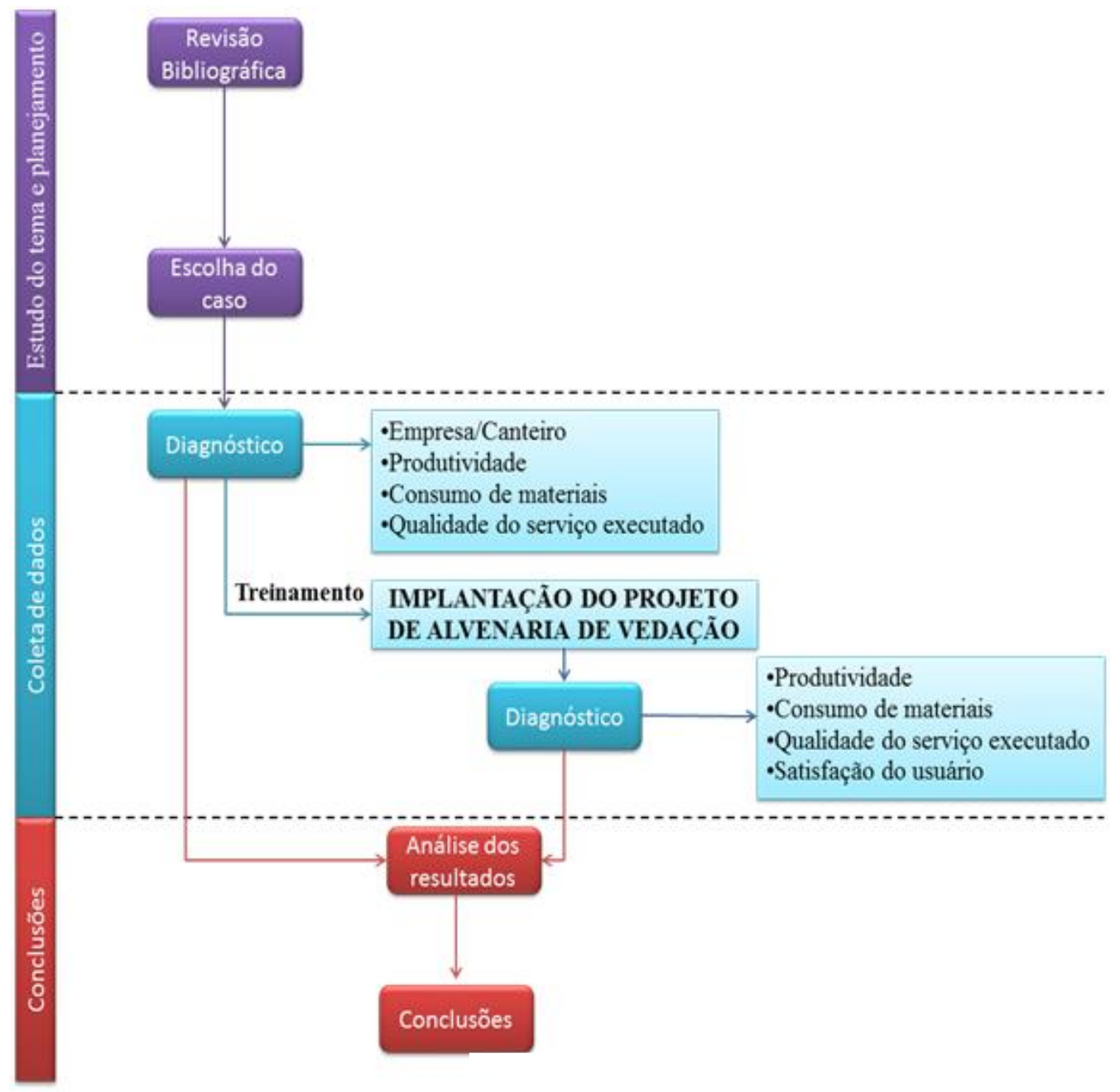

A empresa é uma construtora de médio porte, que atua no mercado goiano desde 1997, com foco em incorporações e construções de edifícios residenciais de médio e alto padrão. $\mathrm{O}$ empreendimento estudado consistiu em três edifícios residenciais localizados na região metropolitana de Goiânia, com área total construída igual a $37.757,21 \mathrm{~m}^{2}$, distribuída em três torres, conforme ilustra a Figura 4. O empreendimento possui 288 unidades habitacionais, e cada torre possui 24 pavimentostipo, além de mezanino, térreo, subsolo e cobertura. A planta baixa do apartamento de três quartos está ilustrada na Figura 5. A entrega da última torre ocorreu em 2012.

A segunda etapa da pesquisa referiu-se à coleta de dados para caracterização da empresa e do empreendimento estudado. Foi realizada por meio de check-lists, cujo objetivo foi levantar as variáveis culturais relativas aos processos adotados para implantação e/ou adaptação ao projeto de produção de alvenaria.

Entre as variáveis coletadas, podem ser citadas desde o nível de mobilização para a qualidade por parte da empresa até a identificação de aspectos de estrutura, tipologia, equipamentos, coordenação modular, registros de fluxos físicos dos materiais, procedimentos de execução e controle referentes ao empreendimento.

Para coletar os dados de produtividade e consumo de materiais, foi elaborado um cartão de produção e consumo em que constavam as anotações de cada elevação executada diariamente. Nesse cartão constavam a data, o horário de medição, a identificação do funcionário, um campo para o número da elevação, a identificação (se a alvenaria é interna ou externa) e, por último, informações quanto ao consumo de blocos cerâmicos na elevação em relação ao projeto (consumo de referência) e em relação à produção (consumo real). 
Figura 4 - Fachadas das 3 torres

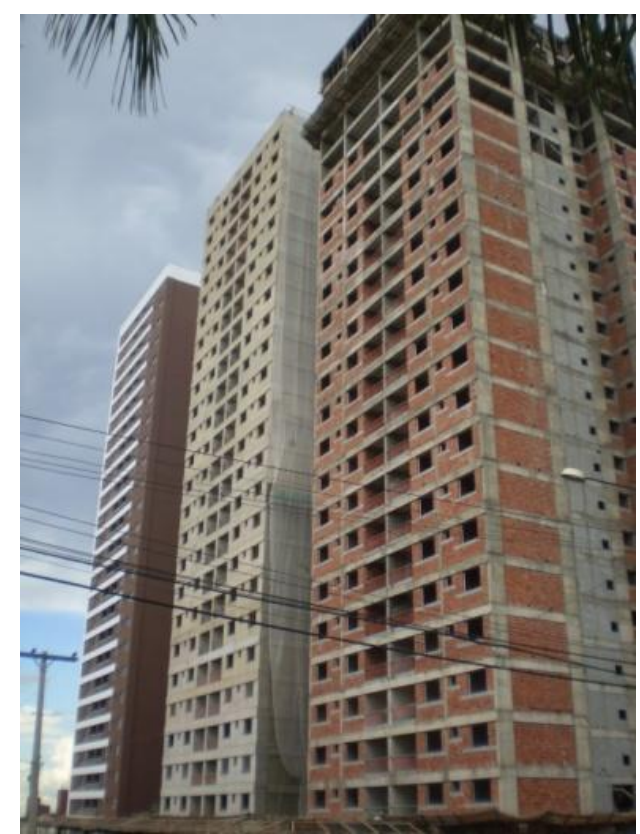

Figura 5 - Planta baixa do apartamento

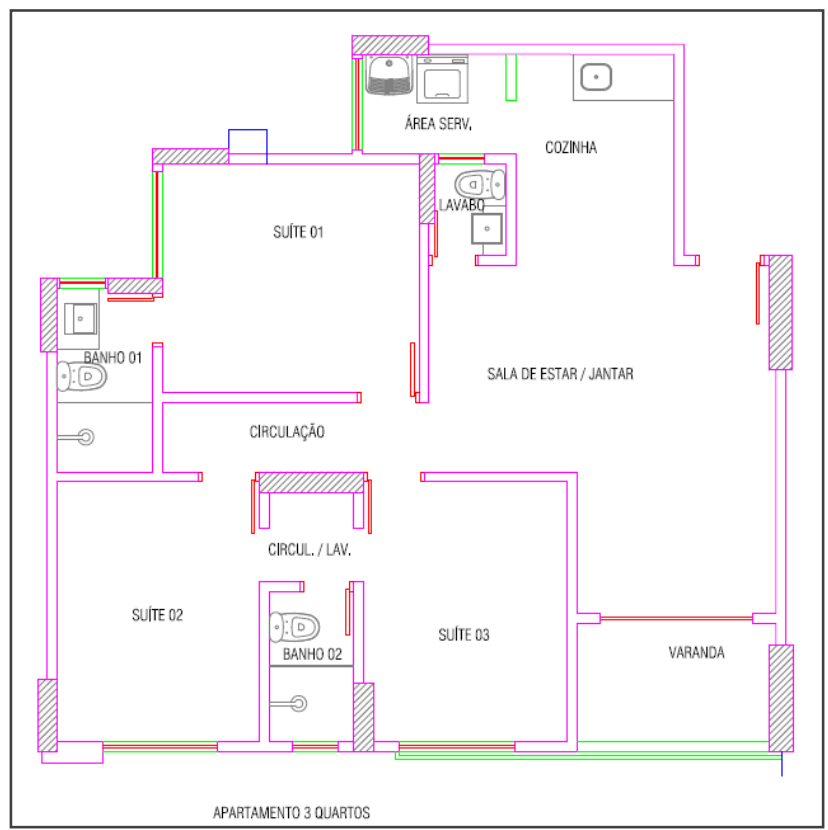

Para relatos sobre ocorrências que se sucederam ao longo da jornada, como, por exemplo, chuva que inviabilizou o serviço, paralisação das atividades por causa de acidente de trabalho ou falta de materiais, o cartão tinha um campo de observações; este tipo de informação foi importante na explicação da variação diária da produtividade.

Para a obtenção das informações sobre a quantidade de alvenaria produzida, as paredes foram enumeradas em planta conforme a Figura 6, e uma legenda faz a descrição dos blocos que eram utilizados para cada parede.

A quantidade de serviço de alvenaria medido era composta da área efetiva de alvenaria, descontando-se todas as aberturas e áreas que não foram preenchidas com argamassa de assentamento e bloco (Figura 7).

86 Brandstetter, M. C. G. de O.; Santos, F. C. dos; Carasek, H. 
Figura 6 - Planta baixa do pavimento-tipo para a coleta de dados

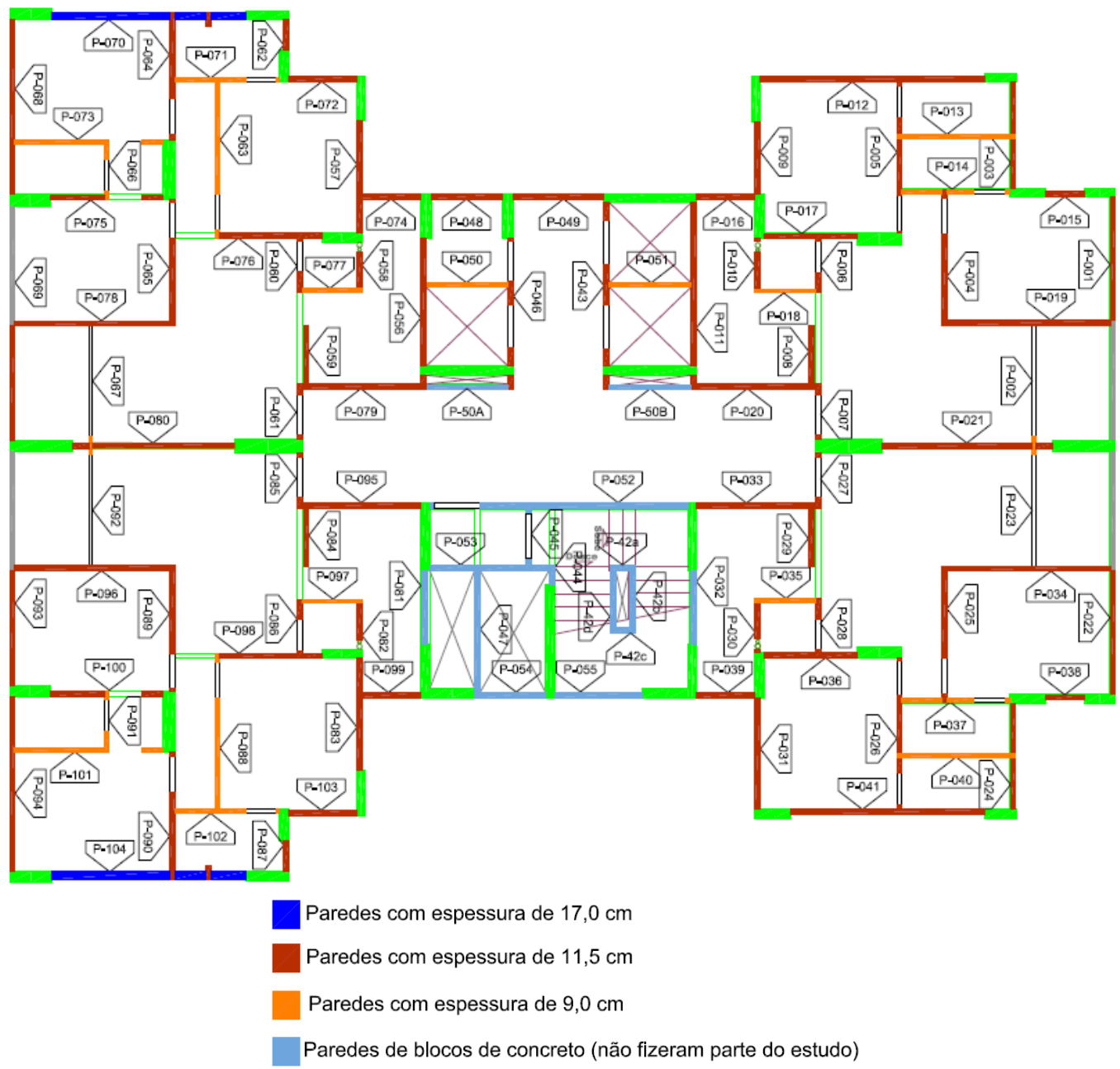

Figura 7 - Quantificação da área líquida de alvenaria para a coleta de dados

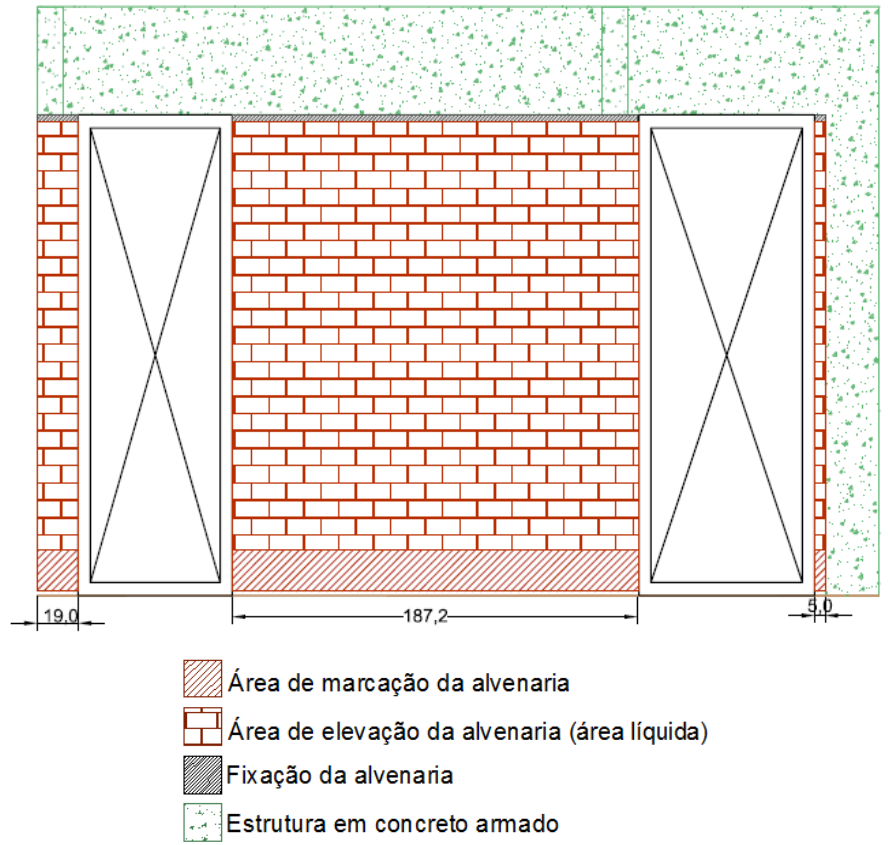


A próxima etapa referiu-se à implantação do projeto de alvenaria de vedação no canteiro de obras. A consolidação do conhecimento produzido nessa atividade durante a pesquisa deu-se por meio de reuniões de treinamento da equipe envolvida e acompanhamento contínuo do processo de utilização do projeto. Essa intervenção ocorreu no sentido de facilitar a aprendizagem e contribuiu para a identificação dos problemas encontrados no projeto.

Em consideração aos dados de entrada, um resumo dos componentes é apresentado na Tabela 2 e na
Tabela 3, onde estão ilustradas imagens relativas aos materiais, etapas principais e equipamentos envolvidos na execução da alvenaria.

As principais delimitações metodológicas para o estudo da produtividade da mão de obra de alvenaria do estudo de caso estão resumidas na Tabela 4.

Para o estudo da perda de blocos de alvenaria do estudo de caso, as delimitações metodológicas estão relacionadas na Tabela 5 .

\section{Tabela 2 - Tipos de componentes relacionados no estudo de caso}

\begin{tabular}{|c|c|c|c|c|c|}
\hline 루의 & 물 & 를 & $\begin{array}{c}\text { Blocos com largura de } 9 \mathrm{~cm} \text { sendo: } \\
(9 \times 19 \times 9) \mathrm{cm} ;(9 \times 19 \times 14) \mathrm{cm} ; \\
(9 \times 19 \times 19) \mathrm{cm}\end{array}$ & & $\begin{array}{l}\text { Tijolo maciço (dimensões: } \\
\qquad 9 \times 19 \times 4,5) \mathrm{cm}\end{array}$ \\
\hline & & & & & $\begin{array}{c}\text { Canaleta de concreto } \\
\text { (dimensões: } \\
11,5 \times 19 \times 39) \mathrm{cm}\end{array}$ \\
\hline
\end{tabular}

Tabela 3 - Equipamentos e etapas da execução relativos à alvenaria do estudo de caso

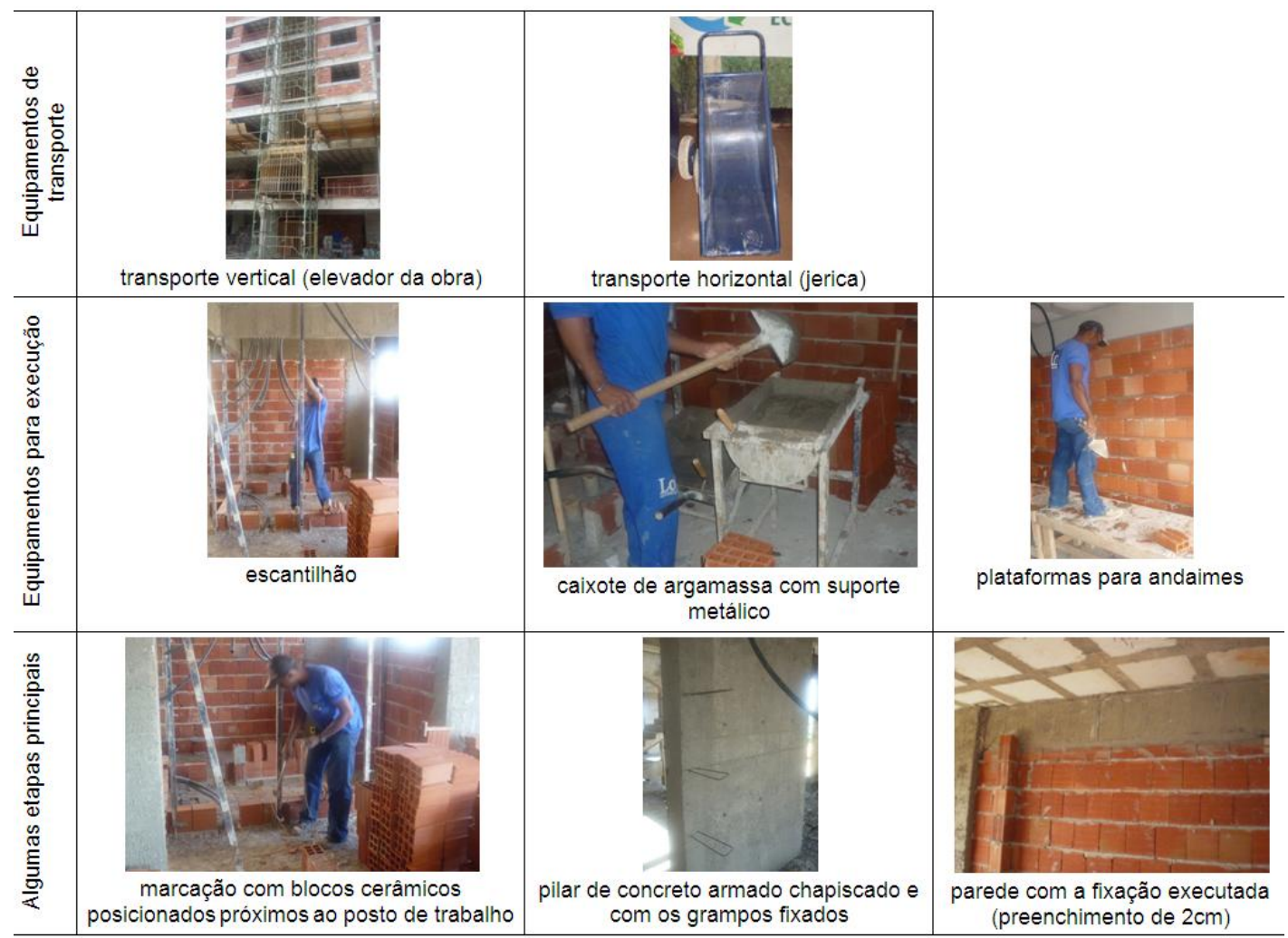

88 Brandstetter, M. C. G. de O.; Santos, F. C. dos; Carasek, H. 
Tabela 4 - Delimitações metodológicas para o estudo da produtividade

\begin{tabular}{|c|c|}
\hline Mão de obra & $\begin{array}{l}\text { Própria, sendo dividida em quatro equipes formadas por um pedreiro e um ajudante. Cada } \\
\text { equipe era responsável pela execução de um pavimento inteiro. Foram consideradas somente } \\
\text { as horas relativas à elevação da alvenaria. Não foram consideradas para o estudo as horas } \\
\text { relativas às equipes auxiliares de transporte dos materiais. }\end{array}$ \\
\hline $\begin{array}{l}\text { Cálculo do } \\
\text { indicador de } \\
\text { produtividade }\end{array}$ & $\begin{array}{l}\text { RUP (Razão Unitária de Produção), expresso em homens } x \text { hora e a quantidade de serviço } \\
\text { realizado em } \mathrm{m}^{2} \text {. A produtividade foi mensurada com base diária, cumulativa e potencial. }\end{array}$ \\
\hline $\begin{array}{l}\text { Dias de } \\
\text { coleta }\end{array}$ & $\begin{array}{l}\text { As coletas dos dados abrangeram } 26 \text { dias consecutivos para a etapa anterior ao projeto e } 40 \\
\text { dias consecutivos para a etapa posterior à implantação do projeto de alvenaria. }\end{array}$ \\
\hline $\begin{array}{l}\text { Análise } \\
\text { estatística }\end{array}$ & $\begin{array}{l}\text { As análises dos dados consideraram o comparativo dos indicadores de produtividade nas duas } \\
\text { etapas, bem como a aplicação de análises estatísticas com regressões lineares para } \\
\text { verificação de tendências. Foi empregada a Análise de Variância (ANOVA) para verificar } \\
\text { quanto à reta de regressão explica os valores observados utilizados. }\end{array}$ \\
\hline $\begin{array}{l}\text { Fatores de } \\
\text { influência }\end{array}$ & $\begin{array}{l}\text { Para maior rigor científico, buscou-se considerar os fatores potencialmente influenciadores da } \\
\text { produtividade no serviço de alvenaria (elevação) listados na pesquisa de Araújo (2000): } \\
\text { 1. mediana do comprimento das paredes; } 2 \text {. mediana do peso dos blocos; } 3 \text {. densidade de } \\
\text { alvenaria interna; } 4 \text {. tamanho da equipe; } 5 \text {. relação pedreiro: servente; } 6 \text {. dias de duração para } \\
\text { execução de um pavimento; 7. relação entre a área de alvenaria de um pavimento pelo } \\
\text { número de paredes; } 8 \text {. mediana da altura das paredes; } 9 \text {. preenchimento das juntas verticais. }\end{array}$ \\
\hline $\begin{array}{l}\text { Ressalva } \\
\text { metodológica }\end{array}$ & $\begin{array}{l}\text { Com o intuito de isolar os fatores de influência da avaliação comparativa entre as duas etapas } \\
\text { do estudo, foi proposta uma nova delimitação metodológica para a análise dos resultados - } \\
\text { somente uma equipe (equipe 1) foi considerada na análise dos dados. Buscou-se dessa forma } \\
\text { aproximar-se o máximo da condição ceteris paribus, uma vez que a consideração da mesma } \\
\text { equipe, trabalhando sob as mesmas condições, permite a constância dos nove fatores } \\
\text { influenciadores apresentados. Também foram consideradas somente as horas relativas ao } \\
\text { oficial da equipe para o cálculo da produtividade, partindo do pressuposto de que a ferramenta } \\
\text { de racionalização tem influência direta nos oficiais responsáveis pela execução. }\end{array}$ \\
\hline
\end{tabular}

Tabela 5 - Delimitações metodológicas para o estudo da perda

\begin{tabular}{c|l}
\hline Mão de obra & Idem às consideraçães do estudo de produtividade. \\
\hline $\begin{array}{c}\text { Cálculo dos } \\
\text { indicadores } \\
\text { de perda }\end{array}$ & $\begin{array}{l}\text { IC (Indicador de Consumo) - relação entre a quantidade de materiais efetivamente utilizados e } \\
\text { a quantidade de serviço executado, expresso pela relação } C_{\mathrm{REAL}} / \mathrm{QS}\left(\mathrm{b} / \mathrm{bcos}^{2} / \mathrm{m}^{2}\right) ; \\
\text { IP (Indicador de Perda) - mede o distanciamento do desempenho quanto ao uso dos materiais } \\
\text { (bloco cerâmico) em relação a uma situação de referência (projeto de alvenaria), expresso } \\
\text { pela relação }\left(\mathrm{C}_{\mathrm{REAL}}-\mathrm{C}_{\mathrm{REF}}\right) / \mathrm{C}_{\mathrm{REF}}(\%) \text { ). }\end{array}$ \\
\hline $\begin{array}{c}\text { Dias de } \\
\text { coleta }\end{array}$ & Idem às considerações do estudo de produtividade. \\
\hline $\begin{array}{c}\text { Análise } \\
\text { estatística }\end{array}$ & $\begin{array}{l}\text { As análises dos dados abrangeram o comparativo dos indicadores de perda nas duas etapas, } \\
\text { englobando as medidas de tendência central e as medidas de dispersão de cada pavimento } \\
\text { para a mesma equipe 1. Considerando toda a amostra de dados, também foi feita a } \\
\text { comparação estatística por dimensões dos blocos para indicar a maior perda relativa por } \\
\text { material, além da comparação das quantidades totais de blocos utilizados em relação às } \\
\text { quantidades definidas no projeto. Um teste de hipótese foi realizado (Teste T de Student para } \\
\text { amostras em par), contemplando as médias de consumo real de blocos, a mesma equipe e as } \\
\text { mesmas paredes executadas nos dois momentos distintos. }\end{array}$ \\
\hline $\begin{array}{c}\text { Ressalva } \\
\text { metodológica }\end{array}$ & $\begin{array}{l}\text { Para a aproximação da condição de ceteris paribus, manteve-se a delimitação metodológica } \\
\text { de também analisar somente os resultados de uma única equipe (equipe 1) nas análises dos } \\
\text { indicadores amostrais. }\end{array}$ \\
\hline
\end{tabular}

\section{Resultados e discussão}

A análise dos dados coletados da pesquisa procedeu-se em duas fases, comparando-se os dados coletados anterior e posteriormente à utilização do projeto de alvenaria. Essa avaliação levou em conta as oscilações dos resultados diários de produtividade e do consumo de materiais, explicando seus motivos mais evidentes, que podem estar relacionados tanto às características gerenciais do empreendimento quanto às características do operário que realizou o serviço. Com isso, é possível traçar-se um histórico da obra durante o período de pesquisa e contribuir para que se procedam às considerações importantes relativas não apenas ao entendimento da produtividade, bem como à minimização das perdas, mas também às possibilidades de intervenção, com a consequente melhoria da gestão de todo o processo. 
Análise da produtividade da mão de

obraA primeira etapa do estudo contemplou o registro de 26 dias consecutivos de produtividade da equipe. A segunda etapa do estudo contemplou 40 dias.

Para que a análise estatística fosse mais precisa, buscou-se analisar, mediante o emprego de regressão linear, três momentos distintos após a implantação do projeto de alvenaria. Tal escolha ocorreu pelo fato de se buscar isolar os primeiros 11 dias de coleta, nos quais houve maior influência de problemas relacionados à gestão, com enfoque para a logística dos materiais. Posteriormente a esses 11 dias, a mão de obra ficou parada por dez dias, devido à quebra de um elevador de carga, sem possibilidade de abastecimento dos insumos nos pavimentos. Estes dez dias foram eliminados da análise gráfica. Seguiram-se os últimos 19 dias, em que houve uma situação similar à primeira etapa.

Um esquema gráfico da etapa de coleta dos dados é ilustrado na Figura 8.

Os valores de RUP diária, cumulativa e potencial para a Equipe 1 correspondente aos 26 dias de coleta dos dados referentes à etapa anterior à implantação do projeto estão apresentados na Tabela 6.

A análise gráfica e estatística da produtividade da Equipe 1 para os 26 dias de coleta dos dados correspondentes é apresentada na Figura 9.

Pela análise estatística, percebe-se uma correlação forte (próxima a $80 \%$ ), indicando a tendência de piora da produtividade ao longo do tempo. Pela análise de variância, confirmou-se pelo baixo valor do $F$ de significação, inferior ao nível de significância adotado, igual 0,05 , indicando que a regressão é aceita.

Os valores de RUP diária, cumulativa e potencial para a Equipe 1 correspondente aos 30 dias de coleta dos dados referentes à etapa posterior à implantação do projeto está apresentada na Tabela 7.

A análise gráfica e estatística da produtividade da Equipe 1 para os primeiros 11 dias de coleta dos dados correspondentes à etapa posterior à implantação do projeto está apresentada na Figura 10.

Figura 8 - Representação gráfica da etapa de coleta dos dados

\begin{tabular}{|c|c|c|c|c|}
\hline $\begin{array}{c}\text { Baixa percepcão de fatores } \\
\text { relacionados à gestão }\end{array}$ & \begin{tabular}{|c|c|c|} 
Alta percepcão \\
de fatores \\
relacionados à \\
gestão
\end{tabular} & $\begin{array}{c}\text { Paralisação } \\
\text { da execucão } \\
\text { da alvenaria }\end{array}$ & $\begin{array}{c}\text { Baixa percepcão de fatores } \\
\text { relacionados à gestão }\end{array}$ \\
\hline 26 dias & 11 dias & 10 dias & 19 dias \\
\hline
\end{tabular}

Tabela 6 - Valores de produtividade diária, cumulativa e potencial da Equipe 1 na etapa anterior à implantação do projeto

\begin{tabular}{l|c|c|c|c|c|c|c|c|c|c|c|c|c}
\hline \multicolumn{1}{c|}{ Dia } & $\mathbf{1}$ & $\mathbf{2}$ & $\mathbf{3}$ & $\mathbf{4}$ & $\mathbf{5}$ & $\mathbf{6}$ & $\mathbf{7}$ & $\mathbf{8}$ & $\mathbf{9}$ & $\mathbf{1 0}$ & $\mathbf{1 1}$ & $\mathbf{1 2}$ & $\mathbf{1 3}$ \\
\hline RUPd $\left(\mathrm{Hh} / \mathrm{m}^{2}\right)$ & 0,25 & 0,22 & 0,37 & 0,30 & 0,25 & 0,72 & 0,5 & 0,43 & 0,43 & 0,33 & 0,33 & 0,46 & 0,55 \\
\hline RUPcum $\left(\mathrm{Hh} / \mathrm{m}^{2}\right)$ & 0,25 & 0,24 & 0,28 & 0,29 & 0,27 & 0,30 & 0,32 & 0,33 & 0,33 & 0,33 & 0,33 & 0,34 & 0,35 \\
\hline \hline \multicolumn{1}{c}{ Dia } & $\mathbf{1 4}$ & $\mathbf{1 5}$ & $\mathbf{1 6}$ & $\mathbf{1 7}$ & $\mathbf{1 8}$ & $\mathbf{1 9}$ & $\mathbf{2 0}$ & $\mathbf{2 1}$ & $\mathbf{2 2}$ & $\mathbf{2 3}$ & $\mathbf{2 4}$ & $\mathbf{2 5}$ & $\mathbf{2 6}$ \\
\hline RUPd $\left(\mathrm{Hh} / \mathrm{m}^{2}\right)$ & 0,76 & 0,29 & 0,31 & 0,56 & 0,46 & 0,32 & 0,31 & 0,31 & 0,64 & 0,43 & 0,29 & 0,40 & 0,31 \\
\hline RUPcum $\left(\mathrm{Hh} / \mathrm{m}^{2}\right)$ & 0,36 & 0,35 & 0,35 & 0,36 & 0,36 & 0,36 & 0,36 & 0,35 & 0,36 & 0,36 & 0,36 & 0,40 & 0,36 \\
\hline RUPpot $\left(\mathrm{Hh} / \mathrm{m}^{2}\right)$ & \multicolumn{10}{|c|}{0,31} \\
\hline
\end{tabular}

90 Brandstetter, M. C. G. de O.; Santos, F. C. dos; Carasek, H. 
Figura 9 - Análise gráfica e estatística da produtividade da Equipe 1 na etapa anterior à implantação do projeto

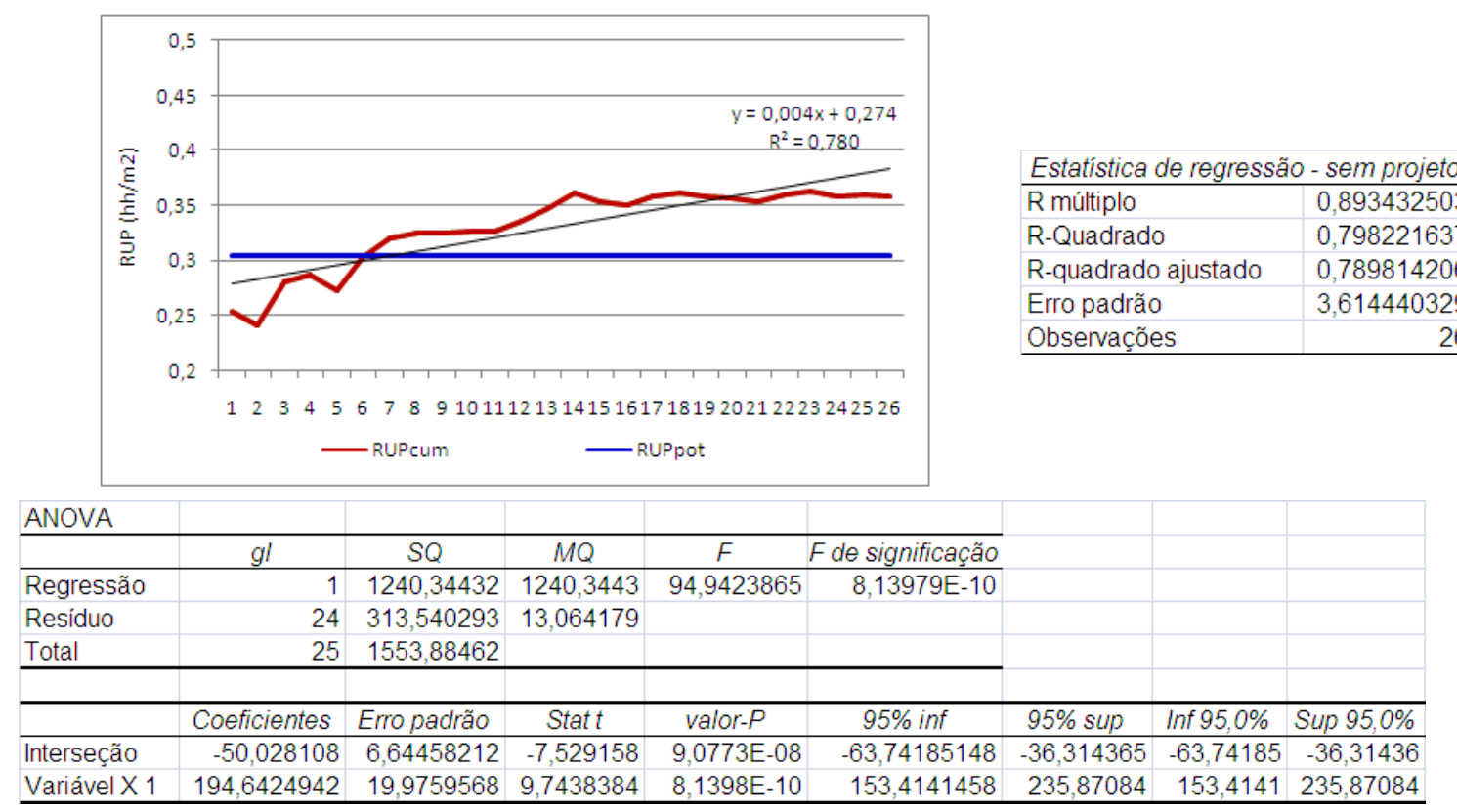

Tabela 7 - Valores de produtividade diária, cumulativa e potencial da Equipe 1 na etapa posterior à implantação do projeto

\begin{tabular}{|c|c|c|c|c|c|c|c|c|c|c|c|c|c|c|c|c|c|c|c|}
\hline Dia ( $1^{0}$ momento) & 1 & 2 & 3 & 4 & 5 & 6 & 7 & 8 & 9 & 10 & 11 & & & & & & & & \\
\hline RUPd $\left(\mathrm{Hh} / \mathrm{m}^{2}\right)$ & 0,38 & 0,34 & 0,26 & 0,44 & 0,57 & 0,48 & 0,54 & 0,42 & 0,58 & 0,54 & 0,36 & & & & & & & & \\
\hline RUPcum $\left(\mathrm{Hh} / \mathrm{m}^{2}\right)$ & 0,38 & 0,36 & 0,32 & 0,34 & 0,37 & 0,38 & 0,40 & 0,40 & \begin{tabular}{|l|}
0,42 \\
\end{tabular} & $\begin{array}{ll}0,43 \\
\end{array}$ & \begin{tabular}{|l|l|}
0,42 \\
\end{tabular} & & & & & & & & \\
\hline Dia $\left(2^{\circ}\right.$ momento $)$ & 1 & 2 & 3 & 4 & 5 & 6 & 7 & 8 & 9 & 10 & 11 & 12 & 13 & 14 & 15 & 16 & 17 & 18 & 19 \\
\hline RUPd $\left(\mathrm{Hh} / \mathrm{m}^{2}\right)$ & 0,20 & 0,26 & 0,23 & 0,47 & 0,33 & 0,33 & 0,31 & 0,31 & 0,42 & 0,37 & 0,35 & 0,24 & 0,24 & 0,31 & 0,25 & 0,27 & 0,26 & 0,29 & 0,40 \\
\hline RUPcum $\left(\mathrm{Hh} / \mathrm{m}^{2}\right)$ & 0,38 & 0,37 & 0,35 & 0,36 & \begin{tabular}{|l|}
0,36 \\
\end{tabular} & 0,36 & 0,35 & 0,35 & \begin{tabular}{|l|}
0,35 \\
\end{tabular} & 0,35 & \begin{tabular}{|l|}
0,35 \\
\end{tabular} & 0,35 & 0,35 & 0,35 & \begin{tabular}{|l|l|}
0,34 \\
\end{tabular} & 0,34 & 0,33 & 0,33 & 0,33 \\
\hline RUPpot $\left(\mathrm{Hh} / \mathrm{m}^{2}\right)$ & & & & & & & & & & 0,26 & & & & & & & & & \\
\hline
\end{tabular}

Figura 10 - Análise gráfica e estatística da produtividade da Equipe 1 no primeiro momento da etapa posterior à implantação do projeto

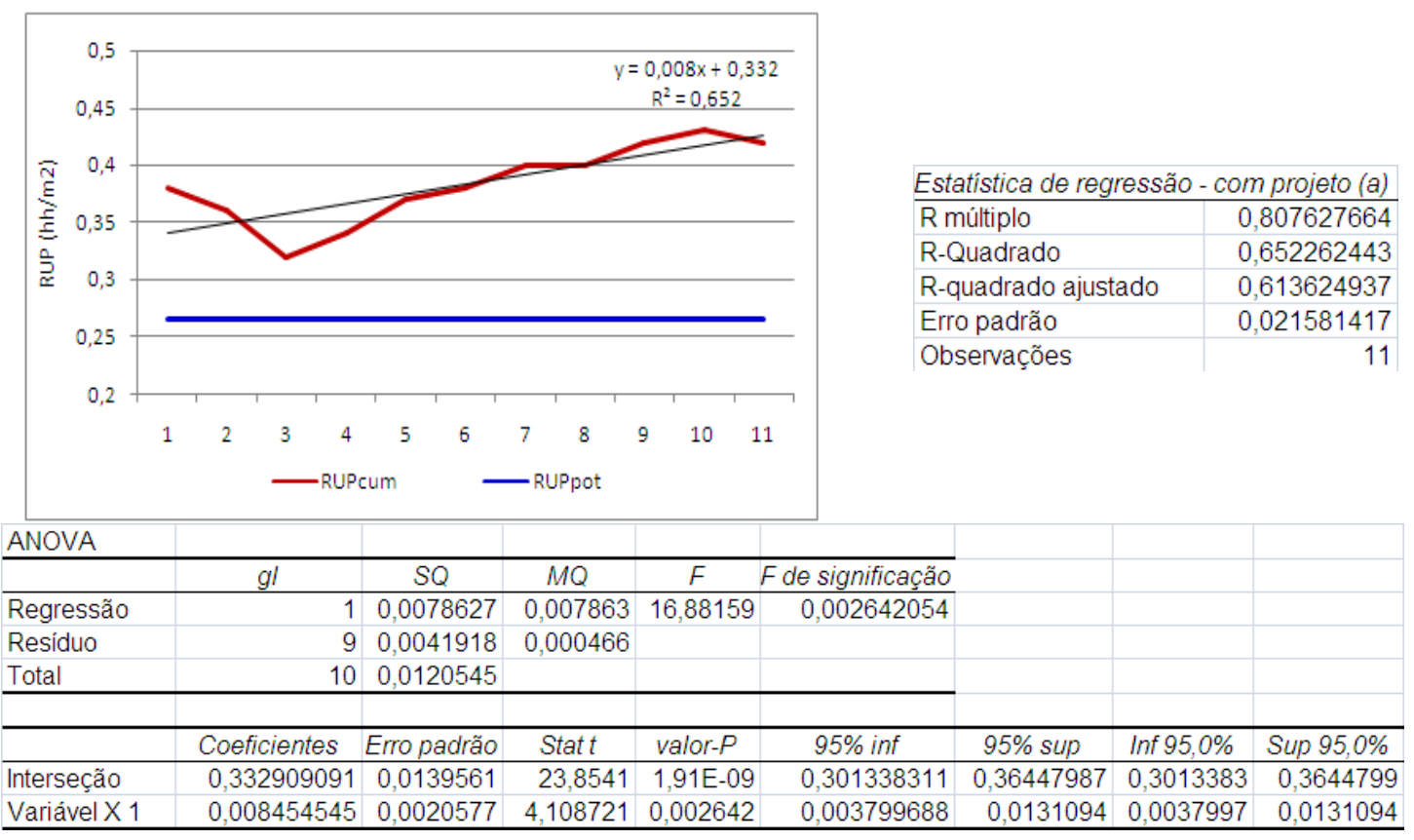


Percebe-se uma correlação moderada para esse primeiro momento após a implantação do projeto. Conforme mencionado anteriormente, neste período foram observados aspectos influenciadores da produtividade relacionados à gestão, em especial à logística. A mesma tendência de piora da produtividade foi percebida, como na etapa anterior. Apesar da menor correlação, a regressão é aceita pelos indicadores calculados na ANOVA. Após esse período, seguiram-se dez dias em que a mão de obra esteve disponível para o trabalho, porém o mesmo não foi executado por problemas de paralisação do elevador de carga.

A análise gráfica e estatística da produtividade da Equipe 1 para os 19 dias de coleta dos dados correspondentes à etapa posterior à implantação do projeto está apresentada na Figura 11.

Pela análise estatística, percebe-se uma correlação forte $(80 \%)$, indicando a tendência de melhora da produtividade ao longo do tempo. Pela análise de variância, a regressão é aceita, pela confirmação do baixo valor do $\mathrm{F}$ de significação, inferior ao nível de significância adotado, igual 0,05.

Considerando todo o período de coleta dos dados e comparando-se as duas etapas, antes e depois da implantação do projeto de alvenaria, pôde-se constatar que o valor da $\mathrm{RUP}_{\text {cumulativa }}$ passou de $0,36 \mathrm{Hh} / \mathrm{m}^{2}$ para $0,33 \mathrm{Hh} / \mathrm{m}^{2}$, porém o maior incremento pode ser observado na diminuição da $\mathrm{RUP}_{\text {potencial }}$ de $0,31 \mathrm{Hh} / \mathrm{m}^{2}$ para $0,26 \mathrm{Hh} / \mathrm{m}^{2}$. Com a regressão linear, pôde-se comprovar a melhoria da produtividade, com a tendência do efeito aprendizado ao longo do tempo.

\section{Perdas e consumo unitário de blocos}

Para a análise do consumo de blocos cerâmicos, o cálculo dos indicadores globais passou pela contabilização dos blocos cerâmicos utilizados nas elevações $\left(\mathrm{Q}_{\mathrm{REAL}}\right.$ ou quantidade real), a previsão dada em projeto $\left(\mathrm{Q}_{\mathrm{REF}}\right.$ ou quantidade de referência) e a quantidade de serviço executado em cada pavimento.

$\mathrm{Na}$ Tabela 8 estão reunidos os valores de consumo de blocos e perdas da amostra estudada referente à fase sem a utilização do projeto, considerando somente a Equipe 1, destacando-se as medidas de tendência central (média aritmética e mediana) e as medidas de dispersão ( $\Delta \mathrm{m}$ ou amplitude total e desvio padrão) de cada pavimento. De modo similar, os valores correspondentes ao consumo e perdas para a mesma equipe nos pavimentos em que foram executadas as elevações após a implantação do projeto estão apresentados na Tabela 9.

\section{Figura 11 - Análise gráfica e estatística da produtividade da Equipe 1 no segundo momento da etapa posterior à implantação do projeto}

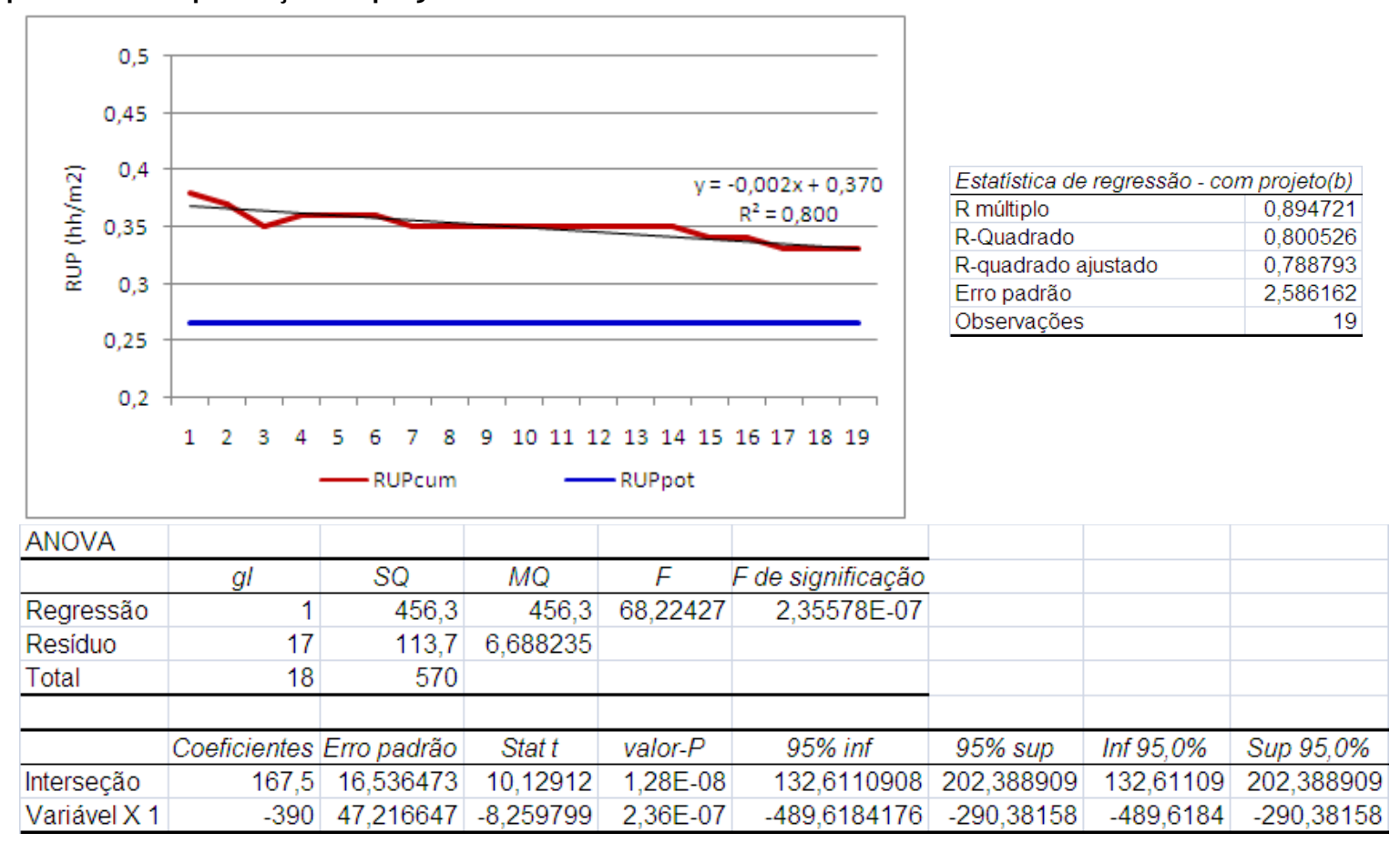

92 Brandstetter, M. C. G. de O.; Santos, F. C. dos; Carasek, H. 
Tabela 8 - Análise estatística amostral: valores de consumo real e perda de blocos (\%) para a Equipe 1 sem utilização do projeto de alvenaria

\begin{tabular}{c|c|c|c|c|c|c|c|c|c}
\cline { 3 - 10 } \multicolumn{2}{c|}{} & \multicolumn{3}{c|}{ IC $\left(\mathbf{C}_{\text {real }} / \mathbf{Q S}\right)$ (blocos/m $\left./ \mathbf{m}^{2}\right)$} & \multicolumn{3}{c}{ IP $\left(\mathbf{C}_{\text {real }}-\mathbf{C}_{\text {ref }}\right) / \mathbf{C}_{\text {ref }}$} \\
\hline $\begin{array}{c}\text { pavimento } \\
\text { s/ projeto }\end{array}$ & $\begin{array}{c}\mathrm{n}^{0} \\
\text { paredes }\end{array}$ & $\Delta \mathrm{m}$ & média & $\begin{array}{l}\text { desvio } \\
\text { padrão }\end{array}$ & mediana & $\Delta \mathrm{m}$ & média & $\begin{array}{l}\text { desvio } \\
\text { padrão }\end{array}$ & mediana \\
\hline 6 & 48 & 16,48 & 26,75 & 3,66 & 25,75 & 32,63 & 2,10 & 5,03 & 0,29 \\
\hline 7 & 88 & 23,40 & 27,22 & 3,98 & 26,09 & 32,89 & 2,59 & 5,44 & 0,92 \\
\hline
\end{tabular}

Tabela 9 - Análise estatísticas amostrais: valores de consumo real e perda de blocos (\%) para a Equipe 1 com a utilização do projeto de alvenaria

\begin{tabular}{|c|c|c|c|c|c|c|c|c|c|}
\hline \multirow[b]{2}{*}{$\begin{array}{l}\text { pavimento } \\
\mathrm{c} / \text { projeto }\end{array}$} & \multirow[b]{2}{*}{$\begin{array}{c}n^{0} \\
\text { paredes }\end{array}$} & \multicolumn{4}{|c|}{ IC $\left(C_{\text {real }} / Q S\right)$ (blocos $\left./ \mathrm{m}^{2}\right)$} & \multicolumn{4}{|c|}{ IP $\left(C_{\text {real }}-C_{\text {ref }}\right) / C_{\text {ref }}$} \\
\hline & & $\Delta \mathrm{m}$ & média & $\begin{array}{l}\text { desvio- } \\
\text { padrão }\end{array}$ & mediana & $\Delta \mathrm{m}$ & média & $\begin{array}{l}\text { desvio- } \\
\text { padrão }\end{array}$ & mediana \\
\hline 10 & 28 & 20,84 & 25,06 & 4,23 & 24,83 & 13,67 & $-2,24$ & 3,42 & 0 \\
\hline 11 & 77 & 24,93 & 25,48 & 4,67 & 25,42 & 40,91 & $-3,26$ & 7,81 & 0 \\
\hline 13 & 92 & 25,86 & 25,90 & 4,09 & 25,72 & 23,64 & $-1,36$ & 4,82 & 0 \\
\hline
\end{tabular}

A observação dos dados do indicador de consumo comprova médias menores do número de blocos efetivamente utilizados por metragem quadrada de alvenaria, após o uso do projeto. Os resultados negativos das médias do indicador de perda indicam que não houve perdas, e sim economia de blocos cerâmicos, indicando que a utilização do projeto foi positiva também entre as equipes.

A principal questão para ter números negativos de perdas, ou seja, um índice de economia, deu-se pelo fato de que os blocos cerâmicos fornecidos possuíam dimensões variadas, conforme mostrado na Figura 12.

No decorrer da pesquisa não foi possível alterar o fornecedor de blocos cerâmicos da obra, devido à existência de um contrato de permuta entre a construtora e o fabricante. Podem-se destacar também as perdas que ocorreram por dimensões de bloco, conforme apresentado na Tabela 10.

Ao analisarem-se as elevações por tipo de bloco, ou seja, pela espessura da parede, foi possível observar que, para os blocos de $9,0 \mathrm{~cm}$ e $11,5 \mathrm{~cm}$, a média do índice de perda foi negativa após o uso do projeto, significando que houve economia de blocos cerâmicos. Também é possível constatar-se a redução do índice de consumo de materiais para os três tipos de blocos.

No caso dos blocos cerâmicos com espessura de $17,0 \mathrm{~cm}$, observa-se que houve perda de blocos cerâmicos com essa espessura, mesmo considerando uma amostra menor em comparação com os outros blocos cerâmicos. Essa perda também se justifica pela ausência de módulos cerâmicos para essa espessura.

A análise geral dos dados permite verificar que os índices de perdas obtidos na fase antes e após a utilização do projeto apresentaram diferenças consideráveis, destacando-se o valor médio negativo, que representa um indicador de economia de blocos cerâmicos.

A relação entre as quantidades de blocos cerâmicos utilizados nas elevações $\left(Q_{\text {REAL }}\right)$ e a quantidade especificada no projeto $\left(\mathrm{Q}_{\mathrm{REF}}\right)$, considerando todos os pavimentos estudados, é apresentada na Figura 13. Nota-se que na fase sem projeto $62 \%$ dos casos estão relacionados às elevações que utilizaram a quantidade de blocos superior àquela relacionada ao projeto.

Considerando os dados obtidos em projeto, foram contabilizados que em sete pavimentos estudados perderam-se 1.142 unidades de blocos cerâmicos, ressaltando que foram estudados apenas os blocos utilizados nas elevações.

Foi possível observar que, após a implantação do projeto de alvenaria de vedação, a porcentagem de elevações que tiveram um consumo real de blocos cerâmicos superior ao valor de referência em projeto reduziu para $20 \%$. Nota-se que $80 \%$ das elevações tiveram um consumo real menor ou igual ao consumo de referência. Essa porcentagem, considerando os dados em projeto, corresponde a 849 blocos, que estavam previstos no consumo de referência mas que não foram utilizados. 
Figura 12 - Exemplos de diferentes comprimentos e cores dos blocos

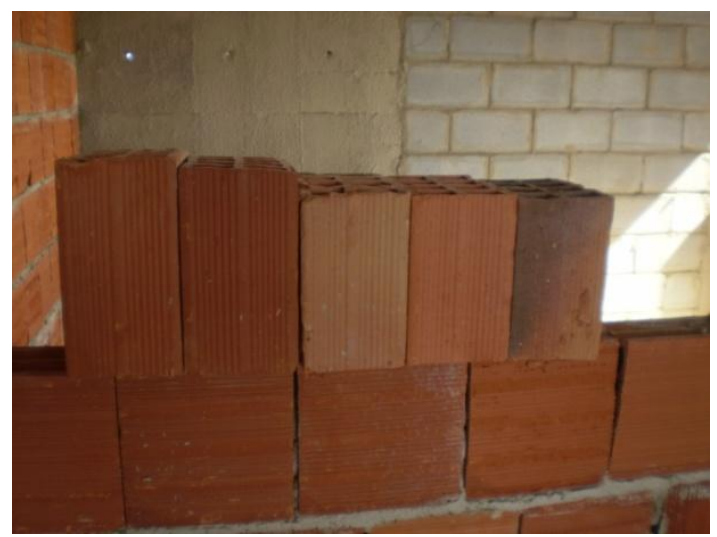

Tabela 10 - Comparação estatística por dimensões dos blocos antes e após a implantação do projeto de alvenaria

\begin{tabular}{|c|c|c|c|c|c|}
\hline \multirow[b]{2}{*}{$\begin{array}{c}\text { Blocos cerâmicos } \\
(\mathrm{cm})\end{array}$} & \multirow[b]{2}{*}{$\begin{array}{c}\mathrm{n}^{0} \\
\text { paredes }\end{array}$} & \multicolumn{2}{|c|}{ IC (un/m²) (sem projeto) } & \multicolumn{2}{|c|}{ IP (\%) (sem projeto) } \\
\hline & & Média & Mediana & Média & Mediana \\
\hline 9,0 & 91 & 25,66 & 25,51 & 2,60 & 1,10 \\
\hline 11,5 & 274 & 27,86 & 26,50 & 3,38 & 1,44 \\
\hline \multirow[t]{2}{*}{17,0} & 8 & 25,57 & 25,55 & 3,50 & 3,39 \\
\hline & & \multicolumn{2}{|c|}{ IC (un/m²) (com projeto) } & \multicolumn{2}{|c|}{ IP (\%) (com projeto) } \\
\hline 9,00 & 69 & 24,14 & 25,06 & $-0,57$ & 0 \\
\hline 11,50 & 238 & 26,02 & 25,56 & $-3,36$ & 0 \\
\hline 17,00 & 6 & 24,76 & 24,71 & 0,21 & 0 \\
\hline
\end{tabular}

Figura 13 - Relação entre as quantidades de blocos cerâmicos utilizados nas elevações e a quantidade especificada em projeto para todos os pavimentos estudados

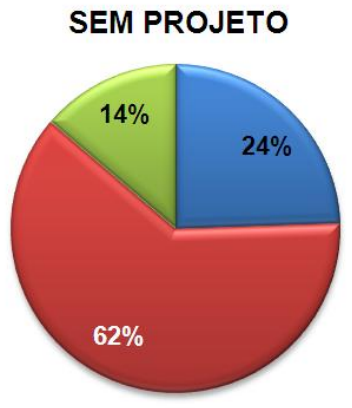

Para atestar o rigor científico, com o intuito de isolar os demais fatores possíveis de influência, uma última análise estatística foi realizada, para comparar ambas as amostras de perdas geradas pela mesma equipe na produção das mesmas paredes nos dois momentos distintos (antes e após a implantação do projeto de alvenaria). Para isso, utilizou-se o teste de hipóteses para as médias com duas populações pareadas (dependentes). A concepção metodológica para realização do Teste $\mathrm{T}$ de Student para duas amostras em par para médias está ilustrada na Figura 14.

\section{COM PROJETO}

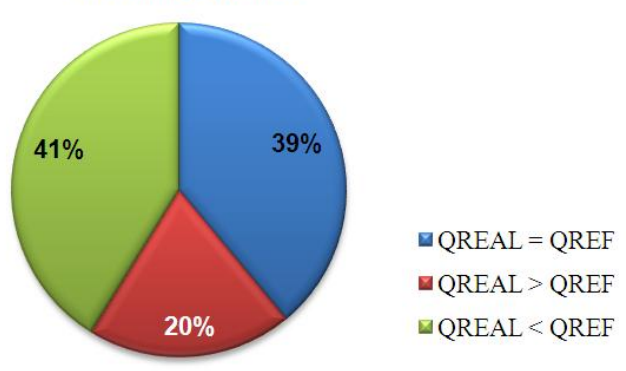

Os resultados do Teste $\mathrm{T}$ para as duas amostras em par para médias estão na Tabela 11.

Percebe-se a correlação forte entre as variáveis pelo coeficiente de Pearson acima de $70 \%$. O valor baixo do índice $\mathrm{P}$ (bicaudal) permite afirmar que as amostras não são homogêneas e que há uma distribuição significativamente diferente nos dois grupos. Esta última análise confirma a diferença entre as duas amostras emparelhadas e permite inferir sobre a significância do indicador de perda de blocos nos dois momentos distintos - antes e após a implantação do projeto de alvenaria. 
Figura 14 - Representação gráfica da concepção metodológica para realização do teste de hipótese T para as duas amostras relativas ao consumo de blocos antes e após o projeto de alvenaria

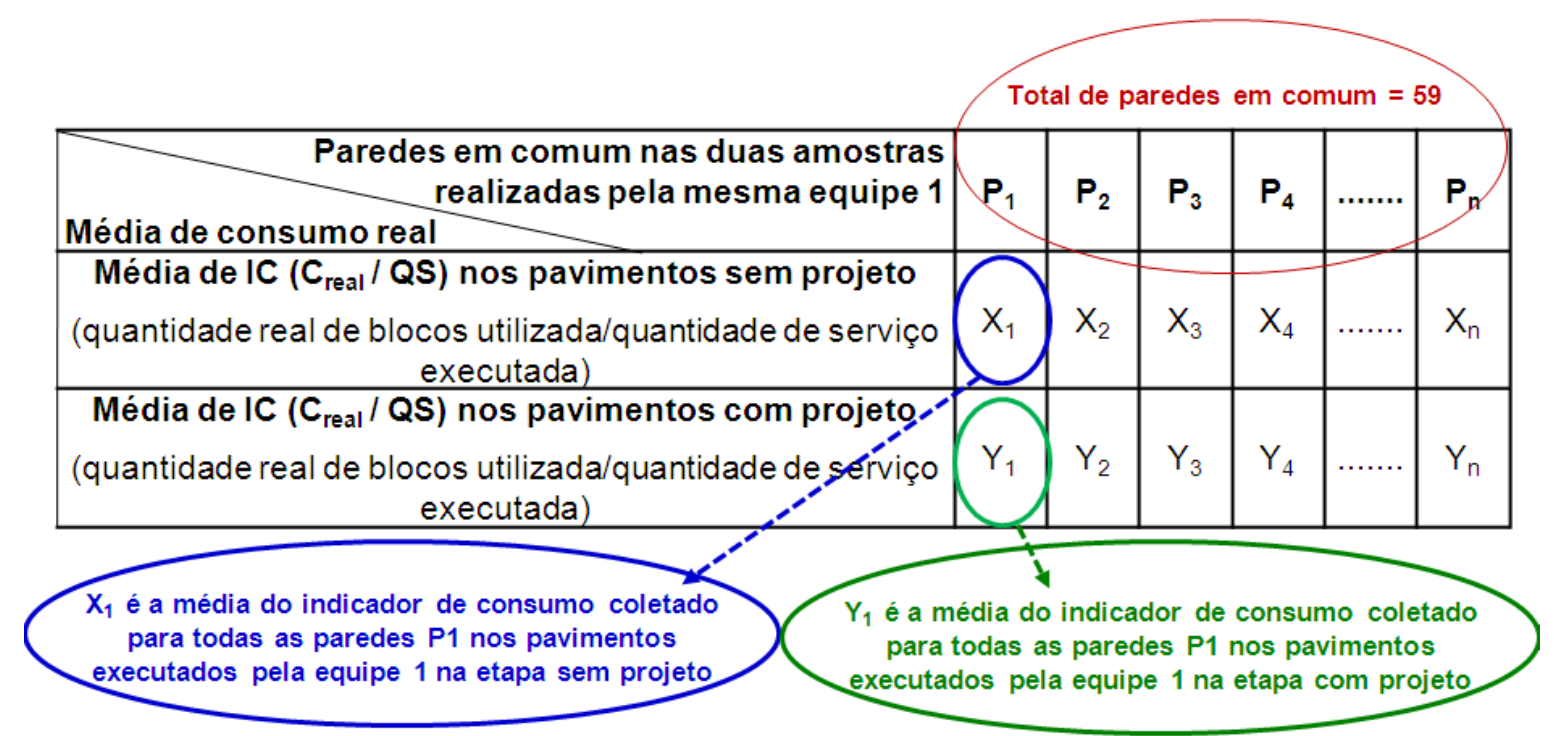

Tabela 11 - Resultados do Teste T para as amostras relativas ao consumo de blocos

Teste T: duas amostras em par para médias

\begin{tabular}{|l|r|r|}
\hline & Variável 1 & Variável 2 \\
\hline Média & 27,76355932 & 25,41388136 \\
\hline Variância & 19,89884835 & 15,84803159 \\
\hline Observações & 59 & 59 \\
\hline Correlação de Pearson & 0 & \\
\hline Hipótese da diferença de média & 58 & \\
\hline gl & 0,735148914 & \\
\hline Stat t & 5,813882269 & \\
\hline $\mathrm{P}(\mathrm{T}<=\mathrm{t})$ unicaudal & $1,37856 \mathrm{E}-07$ & \\
\hline $\mathrm{t}$ crítico unicaudal & 1,671552762 & \\
\hline $\mathrm{P}(\mathrm{T}<=\mathrm{t})$ bicaudal & $2,75712 \mathrm{E}-07$ & \\
\hline $\mathrm{t}$ crítico bicaudal & 2,001717484 & \\
\hline
\end{tabular}

\section{Conclusões}

Diversos são os trabalhos publicados relacionados aos temas centrais do artigo. No entanto, tais pesquisas têm focado seus esforços no diagnóstico da situação vigente da produção das alvenarias de vedação nas obras brasileiras. A presente pesquisa tem como mérito a realização de uma intervenção e posterior quantificação dos benefícios advindos desta.

Em relação ao estudo de produtividade da mão de obra, pôde-se concluir pelo aumento da produtividade, em especial no indicador potencial da equipe. $\mathrm{O}$ aumento ocorreu na ordem de $15 \%$, porém as regressões lineares confirmaram a tendência do efeito aprendizado ao longo do tempo após a implantação do projeto.
Os resultados obtidos em relação ao índice de perda e ao consumo de materiais também deixaram evidentes que o uso do projeto de alvenaria de vedação é vantajoso. O indicador de perda de blocos cerâmicos, gerado pela quebra de blocos no pavimento sem projeto, teve uma média de $2,3 \%$, enquanto, na avaliação após a implantação do projeto de alvenaria de vedação, a média foi de $2,3 \%$, não havendo perda no consumo de blocos cerâmicos, e sim um indicador de economia. Esses valores são aparentemente baixos, sendo inclusive inferiores se comparados aos valores apresentados em outras pesquisas, no entanto cabe ressaltar que foram considerados para o cálculo do indicador somente os blocos cerâmicos utilizados nas elevações de alvenaria e, no caso da análise 
apresentada, os valores referem-se a somente uma única equipe.

Considerando os dados obtidos em projeto, todas as equipes participantes da pesquisa e todos os pavimentos estudados, notou-se que na fase sem projeto $62 \%$ dos casos estão relacionados às elevações que utilizaram a quantidade de blocos superior àquela relacionada ao projeto. Após a implantação do projeto, $80 \%$ das elevações tiveram um consumo real menor ou igual ao consumo de referência, o que comprova a economia quanto ao consumo dos componentes com o emprego do projeto de alvenaria.

Mediante a análise dos resultados, pode-se concluir também que a maioria dos problemas encontrados está diretamente relacionada com questões de caráter gerencial, principalmente, no tocante ao fluxo de materiais dentro do canteiro de obras, tais como a ausência do controle de qualidade em relação aos materiais. Em obras com um controle mais rigoroso quanto à padronização dimensional dos blocos cerâmicos será possível obter resultados ainda mais positivos em relação aos obtidos pela pesquisa.

O trabalho contribuiu para a discussão a respeito da viabilidade do emprego de inovações, no que tange aos aspectos de custo (apresentando tal viabilidade por meio de indicadores de desempenho), bem como evidencia a importância da comunicação entre as etapas de projeto e produção. Os resultados corroboram o ideal da utilização de critérios que assegurem a racionalização da obra e a construtibilidade, o que exige projetos adequados como solução para o cliente, para a realidade gerencial das empresas e que sejam harmônicos entre si.

Assim, percebe-se que, com a implantação do projeto para produção das alvenarias de vedação, pode-se contribuir de forma direta para a redução das perdas e para o aumento da produtividade, mostrando que, além do impacto econômico, a implantação do projeto está intimamente relacionada com questões de sustentabilidade ambiental.

\section{Referências}

ANAND, K. B.; RAMAMURTHY, K.

Laboratory-Based Productivity Study on

Alternative Masonry Systems. Journal of Construction Engineering and Management, v. 129, n. 3, p. 237-242, may/jun. 2003.
ANDRADE, A. C.; SOUZA, U. E. L. Método Para Quantificação de Perdas de Materiais nos Canteiros de Obras de Construção de Edifícios: superestrutura e alvenaria. São Paulo: EPUSP, 2000. Boletim Técnico.

AQUINO, J. P. R.; MELHADO, S. B.

Diagnóstico das Dificuldades no Uso de Projetos Para Produção de Vedações Verticais. São Paulo: EPUSP, 2005. Boletim Técnico.

ARAÚJJ, L. O. C. Método Para a Previsão e Controle da Produtividade da Mão-de-Obra na Execução de Fôrmas, Armação, Concretagem e Alvenaria. 385 f. São Paulo, 2000. Dissertação (Mestrado em Engenharia Civil) - Escola Politécnica, Universidade de São Paulo, São Paulo, 2000.

BARROS, M. M. B. O Processo de Produção das Alvenarias Racionalizadas. In: SEMINÁRIO DE TECNOLOGIA E GESTÃO DA PRODUÇÃO DE EDIFÍCIOS, São Paulo, 1998. Anais... São Paulo: EPUSP/PCC, 1998. p. 21-48.

CARRARO, F. Produtividade da Mão de Obra no Serviço de Alvenaria. 226 f. São Paulo, 1998. Dissertação (Mestrado em Engenharia Civil) Escola Politécnica, Universidade de São Paulo, São Paulo, 1998.

ENSHASSI, A. et al. Benchmarking Masonry Labor Productivity. International Journal of Productivity and Performance Management, v. 56, n. 4, p. 358-368, 2007.

FACHINI, A. C. Subsídios Para Programação da Execução de Estruturas de Concreto Armado no Nível Operacional. São Paulo, SP 214 f. São Paulo, 2005. Dissertação (Mestrado em Engenharia Civil) - Escola Politécnica, Universidade de São Paulo, São Paulo, 2005.

FRANCO, L. S. O Projeto das Vedações Verticais: características e a importância para a racionalização do processo de produção. In: SEMINÁRIO DE TECNOLOGIA E GESTÃO NA PRODUÇÃO DE EDIFÍCIOS, São Paulo, 1998. Anais... São Paulo: EPUSP/PCC, 1998. p. 221-236.

HAMMAD, A. A. A. et al. Factors Affecting Baseline Productivity in Masonry Construction: a comparative study in US, UK and Jordan. Architectural Science Review, jun. 2008.

HEINECK, L. F. M. Efeito Aprendizagem, Efeito Continuidade e Efeito Concentração no Aumento da Produtividade nas Alvenarias. In: SIMPÓSIO DE DESEMPENHO DE MATERIAIS E COMPONENTES DE CONSTRUÇÃO CIVIL, 3., Florianópolis, 1991. Anais... Florianópolis: UFSC, 1991. p. 67-75. 
HOLANDA, E. P. T. de. Novas Tecnologias Construtivas Para Produção de Vedações Verticais: diretrizes para treinamento de mão de obra. 159 f. São Paulo, 2003. Dissertação (Mestrado em Engenharia de Construção Civil e Urbana) - Escola Politécnica, Universidade de São Paulo, São Paulo, 2003.

HWANG, B.; YEO, Z. B. Perception on Benefits of Construction Waste Management in the Singapore Construction Industry. Engineering, Construction and Architectural Management, v. 18, n. 4, p. 394-406, 2011.

LORDSLEEM JUNIOR, A. C. Execução e Inspeção de Alvenaria Racionalizada. 3. ed. São Paulo: O Nome da Rosa, 2000. 98 p.

MARCHIORI, F. F. Desenvolvimento de Um Método Para Elaboração de Redes de Composições de Custo Para Orçamentação de Obras de Edificações. 237 f. São Paulo, 2009. Tese (Doutorado em Engenharia Civil) - Escola Politécnica, Universidade de São Paulo, São Paulo, 2009.

MORTLOCK, D. J.; WHITEHEAD, B.

Productivity in Brick and Block Construction: a literature survey. Building Science, v. 4, p. 179197, 1970.

NÚCLEO DE TECNOLOGIA DAS ARGAMASSAS E REVESTIMENTOS. Caderno de Elevações N-14 ALV-001. Goiânia, 2010. Não publicado.

PALIARI, J. C. Método Para Prognóstico da Produtividade da Mão de Obra e Consumo Unitário de Materiais: sistemas prediais hidráulicos. 661 f. São Paulo, 2008. Tese (Doutorado em Engenharia) - Escola Politécnica, Universidade de São Paulo, São Paulo, 2008.

PEÑA, M. D. Método Para a Elaboração de Projetos Para Produção de Vedações Verticais em Alvenaria. 173 f. São Paulo, 2003. Dissertação (Mestrado em Engenharia Civil) - Escola Politécnica da Universidade de São Paulo, São Paulo, 2003.
SANDERS, S. R.; THOMAS, H. R. Masonry Productivity Forecasting Model. Journal of Construction Engineering and Management, v. 119, p. 163-179, mar. 1993.

SCARDOELLI, L. S.; BICCA, I.; FORMOSO, C. T. Estudo Piloto de Medição de Produtividade Com Utilização da Técnica de Amostragem do Trabalho. In: INTERNATIONAL SEMINAR ON STRUCTURAL MASONRY FOR

DEVELOPING COUNTRIES, 5., Florianópolis, 1994. Proceedings... Florianópolis: UFSC, 1994. p. 509-518.

SILVA, M. M. A. Diretrizes Para Projetos de Alvenarias de Vedação. 274 f. São Paulo, 2003. Dissertação (Mestrado em Engenharia Civil) Escola Politécnica, Universidade de São Paulo, São Paulo, 2003.

SKOYLES, E. R.; SKOYLES, J. R. Waste Prevention on Site. London: Mitchell, 1987. 208 p.

SOUZA, U. E. L. Metodologia Para o Estudo da Produtividade da Mão de Obra no Serviço de Fôrmas Para Estruturas de Concreto Armado. 280 f. São Paulo, 1996. Tese (Doutorado em Engenharia Civil) - Escola Politécnica, Universidade de São Paulo, São Paulo, 1996.

SOUZA, U. E. L. et al. Perdas de Materiais nos Canteiros de Obras: a quebra do mito. Qualidade na Construção, v. 2, n. 13, p. 10-15, 1998.

SOUZA, U. E. L. Como Reduzir Perdas nos Canteiros de Obras: manual de gestão do consumo de materiais na construção civil. São Paulo: Pini, 2005.

SOUZA, U. E. L. Como Aumentar a Eficiência da Mão de Obra: manual de gestão da produtividade na construção civil. São Paulo: Pini, 2006.

THOMAS, H. R.; YIAKOUMIS, I. Factor Model of Construction Productivity. Journal of Construction Engineering and Management, v. 113, n. 4, p. 623-638, 1987.

THOMAZ, E.; HELENE, P. Qualidade no Projeto e na Execução de Alvenaria Estrutural e de Alvenaria de Vedação em Edifícios. São Paulo: EPUSP, 2000. Boletim Técnico. 
Maria Carolina Gomes de Oliveira Brandstetter

Programa de Pós-Graduação em Geotecnia, Estruturas e Construção Civil, Escola de Engenharia Civil | Universidade Federal de Goiás | Praça Universitária, s/n, Setor Leste Universitário | Goiânia - GO - Brasil | CEP 74605-220 | Tel.: (62) 3209-6262 |

E-mail: maria.carolina@uol.com.br

\section{Francielle Coelho dos Santos}

Programa de Pós-Graduação em Geotecnia, Estruturas e Construção Civil, Escola de Engenharia Civil | Universidade Federal de Goiás |

E-mail: franciellecoelho2@hotmail.com

Helena Carasek

Programa de Pós-Graduação em Geotecnia, Estruturas e Construção Civil, Escola de Engenharia Civil | Universidade Federal de Goiás | E-mail: hcarasek@gmail.com

Revista Ambiente Construído

Associação Nacional de Tecnologia do Ambiente Construído

Av. Osvaldo Aranha, $99-3^{\circ}$ andar, Centro

Porto Alegre - RS - Brasil

CEP $90035-190$

Telefone: +55 (51) 3308-4084

Fax: +55 (51) 3308-4054

www.seer.ufrgs.br/ambienteconstruido

E-mail: ambienteconstruido@ufrgs.br

98 Brandstetter, M. C. G. de O.; Santos, F. C. dos; Carasek, H. 